\title{
EL TRATAMIENTO JURÍDICO DEL STALKING DESDE EL PRISMA DE LAS VÍCTIMAS Y LOS PROFESIONALES IMPLICADOS: RESULTADOS DE UN ANÁLISIS CUALITATIVO*
}

\author{
Carolina Villacampa Estiarte** \\ Alejandra Pujols Pérez***
}

Resumen: La incriminación del stalking en 2015 ha determinado la aparición de estudios cuantitativos que permiten constatar la presencia de este fenómeno en España. Los resultados de estas investigaciones revelan que aunque las víctimas explican estos hechos a personas de su entorno, raramente los denuncian. Tal hallazgo determina la conveniencia de analizar el recurso de estas víctimas a los sistemas formales e informales de protección y, más concretamente, el tratamiento

Recibido: enero 2019. Aceptado: marzo 2019

* Este trabajo ha sido realizado en el marco del proyecto I+D DER201564506-C2-1-R "El stalking y los matrimonios forzados como nuevas formas de violencia de género: fenomenología y tutela jurídico-penal".

** Catedrática de Derecho Penal. Orcid ID 0000-0002-1791-8788

Departamento de Derecho Público. Facultad de Derecho de la Universidad de Lleida. Campus de Cappont C. de Jaume II, 73, E-25001, Lleida. E-mail: cvillacampa@dpub.udl.cat

*** Investigadora postdoctoral. Orcid ID 0000-0002-7197-6540 Departamento de Derecho Público. Facultad de Derecho de la Universidad de Lleida. Campus de Cappont C. de Jaume II, 73, E-25001, Lleida. 
que reciben tanto desde el ámbito asistencial como desde el sistema de justicia penal. El presente trabajo, tomando como base 17 entrevistas en profundidad realizadas a víctimas y 27 entrevistas a profesionales, intenta dilucidar cuáles son las necesidades de tutela de las víctimas, de un lado, y cuál es la valoración de la respuesta normativa al stalking, del tratamiento institucional ofrecido y la receptividad a la incorporación de alternativas al proceso penal por parte de los integrantes del estudio, de otro.

Palabras clave: stalking, acoso predatorio, víctimas, profesionales, tratamiento jurídico

\title{
THE LEGAL TREATMENT OF STALKING FROM THE POINT OF VIEW OF THE VICTIMS AND THE PROFESSIONALS INVOLVED: RESULTS FROM A QUALITATIVE ANALYSIS
}

\begin{abstract}
The incrimination of stalking in 2015 has determined the emergence of quantitative studies that verify the existence of this phenomenon in Spain. The results of this research show that although the victims talk about these facts with people around them, they rarely report the incidents to the police. This finding determines the convenience of analysing the victims' use of the formal and informal protection systems and, more specifically, the treatment they receive both from the victim support services and from the criminal justice system. The present paper, on the basis of 17 in-depth interviews with victims and 27 with professionals, aims to elucidate, on the one hand, the victims' protection needs, and on the other hand, the participants' assessment on the legal response to stalking, their opinion about the institutional treatment offered to victims and their receptivity to the incorporation of alternatives to the criminal process.
\end{abstract}

Keywords: stalking, harassment, victims, professionals, legal treatment

\section{Introducción}

La introducción del delito de stalking en Europa se produjo con la aprobación de la Protection from Harassment Act de 1997 en el Reino Unido, extendiéndose posteriormente a algunos de los países de la Europa continental como Austria (2006), Alemania (2007) o Italia (2009), pese a que el verdadero cambio de 
paradigma se ocasionó con la firma del Convenio sobre la prevención y lucha contra la violencia contra las mujeres y la violencia doméstica (Convenio de Estambul) de 2011. La aprobación de esta disposición internacional supuso un sustancial aumento de los países europeos que incorporaron esta figura delictiva en sus textos punitivos, siendo España uno de los últimos en criminalizar específicamente estas conductas. En este sentido, la reforma operada por la LO 1/2015 incorporó un nuevo artículo 172 ter al Código Penal, ubicado entre los delitos contra la libertad de obrar, que incrimina el acoso realizado llevando a cabo de forma insistente y reiterada, sin estar legítimamente autorizado, una serie de conductas taxativamente enumeradas en el precepto alterando gravemente el desarrollo de la vida cotidiana de la víctima.

A diferencia de lo sucedido en otros países europeos ${ }^{1}$, la incorporación de este tipo delictivo a nuestro texto punitivo se realizó sin contar con información empírica que permitiera conocer la prevalencia y las características de estos comportamientos. Tanto es así que hasta el momento únicamente 3 estudios, 2 de los cuales realizados exclusivamente con muestras de estudiantes universitarios, han focalizado su atención en esta cuestión en España. Pese a lo escaso de los datos, la prevalencia de victimización detectada por estos estudios, que ha sido del $11 \%$ en población general ${ }^{2}$ y de entre el $14 \%^{3}$ y el $40 \%$ en po-

1 Vid. Isituto Nazionale di Statistica: La violenza e i maltrattamenti contro le donne dentro e fuori la famiglia. Anno 2006, Roma, 2007, p. 3. Accesible en: https://www.istat.it/it/files//2011/07/testointegrale.pdf; Hoffmann, J.: Stalking, Springer, Heidelberg, 2006, passim; Office for National StatisTICS: «Intimate Personal Violence and Partner Abuse», en Focus on Violent Crime and Sexual Offences: Year ending March 2015, 2016, pp. 20-21; Scottish Government Social Research: Scottish Crime and Justice Survey 2014/15: Sexual Victimisation and Stalking, Edimburgo, 2016, p. 3.

2 Vid. FRA - European Union Agency for Fundamental Rights: Violence against women: an EU-wide survey. Main results, Publications Office of the European Union, Luxemburgo, 2015, p. 83.

3 Vid. Bodelon, E. / Igareda, N. / CAsas, G.: Violencia sexual, acoso y miedo al delito. Informe Español, Barcelona, 2012, p. 15. Accesible en: http://www. gendercrime.eu/pdf/gendercrime_country_report_spain_spanish.pdf. 
blación universitaria -si bien en este último caso con una tasa de auto-identificación de únicamente el $13,1 \%{ }^{-4}$, permite constatar la concurrencia de stalking también aquí.

Los resultados arrojados por estas investigaciones, además de aportar datos acerca de la prevalencia y la caracterización del fenómeno, se centran en averiguar las estrategias de afrontamiento emprendidas por las víctimas. Al respecto, tomando la delación como específica medida de afrontamiento, revelan que la mayor parte de las víctimas -concretamente entre el $60,5 \%{ }^{5}$ y el $93,4 \%{ }^{6}$ de las mismas- explican lo sucedido a alguien, cosa que podría indicar una cierta propensión de estas a buscar apoyo y asistencia informal. Contrasta con la elevada tasa de delación objetivada la reducida tasa de denuncia observada -situada en el $19,1 \%$ de los casos en estudiantes universitarios ${ }^{7}$ y en el $26 \%$ en población general ${ }^{8}$. . Preguntadas las víctimas por cuál era el motivo de la ausencia de denuncia, refirieron principalmente bien que se trataba de una situación que podía ser resuelta sin acudir a la policía (45\%), bien que los hechos no eran lo suficientemente graves para ser denunciados (35\%). Junto a ello, sin embargo, hasta un $18 \%$ de las víctimas afirmó que el motivo para no denunciar consistía en la creencia de que la policía no podría hacer nada o que, aun pudiendo, no haría nada para ayudarlas ${ }^{9}$.

4 Vid. Villacampa Estiarte, C. / Pujols Pérez, A.: «Prevalencia y dinámica de la victimización por stalking en población universitaria», en Revista Española de Investigación Criminológica, $\mathrm{n}^{\circ} 15,2017$, p. 9.

5 Vid. Bodelon, E. / Igareda, N. / Casas, G.: Violencia sexual, acoso y miedo al delito. Informe Español, op. cit., p. 19.

6 Vid. Villacampa Estiarte, C. / Pujols Pérez, A.: «Stalking: efectos en las víctimas, estrategias de afrontamiento y propuestas legislativas derivadas», en Indret: Revista para el Análisis del Derecho, n², 2017, p. 20.

7 Cfr. Villacampa Estiarte, C. / Pujols Pérez, A.: o. u. c., p. 22.

8 Vid. FRA - European Union Agency for Fundamental Rights: Violence against women: an EU-wide survey. Main results, op. cit., p. 91.

9 Vid. FRA - European Union Agency for Fundamental Rights: o. u. c., p. 92 . 
Más allá de los datos cuantitativos indicados, ningún estudio en España se ha centrado en analizar el recurso de las víctimas de stalking a los sistemas formales e informales de protección ni, más concretamente, el tratamiento que reciben tanto desde el ámbito asistencial como desde el propio sistema de justicia penal. Consultados los estudios que versan sobre esta cuestión a nivel internacional, estos revelan una deficiente detección de las víctimas de stalking, debida tanto a la falta de formación de los profesionales como a la vinculación prácticamente exclusiva del fenómeno con la violencia doméstica, lo que provoca la invisibilización de manifestaciones del mismo que se dan en otros contextos ${ }^{10}$. Otro de los problemas comúnmente apuntados por tales investigaciones son las dificultades de las víctimas para obtener medidas de protección, constatándose que deben recorrer un camino excesivamente arduo para su consecución ${ }^{11}$. Junto a ello, las víctimas del fenómeno advierten que la atención recibida por parte del sistema de justicia penal y de los servicios asistenciales no cubre sus principales necesidades, apuntando especialmente a la inadecuada atención que reciben de los profesionales de estos servicios, que trivializan su situación y no les ofrecen la información y la protección que precisan ${ }^{12}$.

10 Vid. Cox, L. / Speziale, B.: «Survivors of Stalking. Their Voices and Lived Experiences», en Affilia: Journal of Women and Social Work, vol. 24, $\mathrm{n}^{\circ}$, 2009, pp. 15-16 y Morris, S. / Anderson, S. / Murray, L.: Stalking and Harassment in Scotland, Scottish Executive Social Research, Edimburgo, 2002, p. 71.

11 Vid. Klein, A. / Salomon, A. / Huntington, N. / Dubois, J. / Lang, D.: A Statewide Study of Stalking and Its Criminal Justice Response, NCJ Publication \# 228354, National Institute of Justice, U.S. Department of Justice, Sudbury, 2009, pp. 27 y ss. y Morris, S. / Anderson, S. / Murray, L.: Stalking and Harassment in Scotland, op. cit., pp. 80 y ss.

12 Vid. Brewster, M. P.: Exploration of the Experiences and Needs of Former Intimate Stalking Victims, Final Report Submitted to the National Institute of Justice, US Department of Justice, West Chester, 1998, p. 9; FINCH, E.: The Criminalisation of Stalking: Constructing the Problem and Evaluating the Solution, Cavendish Publishing, Londres, 2001, pp. 253 y ss.; GalEAzzi, G. M. / Bučar-Ručman, A. / DeFazio, L. / Groenen, A.: «Experiences of Stalking Victims and Requests for Help in Three European Countries. 


\section{Objetivos}

Verificada la escasez de estudios que versan sobre esta cuestión, así como los problemas inherentes a los sistemas tuitivos denunciados por víctimas y profesionales, decidió emprenderse un estudio empírico cualitativo tanto con personas que habían pasado por un proceso de victimización de este tipo como con profesionales que hubieran o pudieran haber estado en contacto con dichas víctimas. Los objetivos de esta investigación fueron: (1) conocer las necesidades de tutela de las víctimas de stalking y los motivos para no denunciar los hechos, (2) analizar el tratamiento institucional ofrecido a este tipo de víctimas a través de la valoración del conocimiento de determinados grupos profesionales sobre este proceso de victimización y de su capacidad para detectar a estas concretas víctimas, (3) conocer

A survey», en European Journal on Criminal Policy and Research, vol. 77, 2009, pp. 250 y ss.; KorkodeILOU, J.: «Dealing with the unknown: Learning from stalking victims' experiences», en Crime Prevention and Community Safety: An International Journal, vol. 16, nº4, 2014, pp. 261 y ss.; KorKoDEILOU, J.: «Stalking victims, victims of sexual violence and criminal justice system responses: is there a difference or just 'business as usual'?», en British Journal of Criminology, vol. 56, 2016, pp. 260-267; Melton, H. C.: «Stalking in the context of Intimate Partner Abuse. In the Victims' Words», en Feminist Criminology, vol. 2, nº 4, 2007, pp. 351 y ss.; NikUPeTERI, A.: «Stalked lives: Finnish women's emotional experiences of post-separation stalking», en Nordic Social Work Research, vol. 7, 2017, pp. 6 y ss.; PuRCell, R. / Pathé, M. / Mullen, P. E.: «The Prevalence and Nature of Stalking in the Australian Community», en Australian and New Zealand Journal of Psychiatry, vol. 36, 2002, pp. 117 - 119; Sheridan, L. / Davies, G.M. / Boon, J. C. W.: «The Course and Nature of Stalking: A Victim Perspective», en The Howard Journal, vol. 40, n³, 2001, pp. 229-231; TAYLOR-DunN, H. / Bowen, E. / Gilchrist, E. A.: «Reporting Harassment and Stalking to the Police: A Qualitative Study of Victims' Experiences», en Journal of Interpersonal Violence, vol. 22, 2018, pp. 10-20; van DER AA, S. / Groenen, A.: «Identifying the Needs of Stalking Victims and the Responsiveness of the Criminal Justice System: A Qualitative Study in Belgium and the Netherlands», en Victims and Offenders, vol. 6, 2010, pp. 19 y ss. y WorsLey, J. D. / Wheatcroft, J. M. / Short, E. / Corcoran, R.: «Victims' Voices: Understanding the Emotional Impact of Cyberstalking and Individuals' Coping Responses», en SAGE Open, 2017, pp. 6-9. 
la valoración que víctimas y profesionales efectúan de los mecanismos legales existentes tanto en atención a la respuesta jurídico-penal ofrecida a esta realidad como a las medidas judiciales de protección y (4) explorar su receptividad a la incorporación de nuevos procesos bien de justicia restaurativa bien de carácter tuitivo alternativos al proceso penal en la respuesta ofrecida por el ordenamiento jurídico frente a estos comportamientos.

\section{Metodología}

Para el análisis de las cuestiones planteadas se utilizó exclusivamente metodología cualitativa por considerarse la más adecuada para cumplir con los objetivos de la investigación, al permitir estudiar los fenómenos sociales en el propio entorno donde se producen, sin distorsionar la realidad, posibilitando así una mayor aproximación al fenómeno estudiado ${ }^{13}$.

\section{a) Muestra}

Se trabajó con dos muestras, la primera de ellas compuesta por víctimas. En lo que a esta submuestra se refiere, fue obtenida a través de una encuesta de victimización realizada a un total de 1.162 estudiantes universitarios que en el momento de la recogida de datos se hallaban cursando los grados en derecho, criminología e investigación privada en las comunidades autónomas de Catalunya o Comunidad Valenciana. De forma que aquellas personas que se auto-identificaron como víctimas de stalking, una vez informadas de la posibilidad de participar en la siguiente etapa de la investigación, podían dejar de forma voluntaria un número de teléfono para que, a posteriori, les fuera realizada una entrevista en profundidad. Todo ello se realizó garantizando el anonimato y sin pedir a la víctima más datos personales que dicho teléfono de contacto o, en su caso,

13 Cfr. Denzin, N.K. / Lincoln, Y.S.: «Introduction. The Discipline and Practice of Qualitative Research», en Denzin, N. K. / Lincoln, Y. S. (Eds.): The Sage Handbook of Qualitative Research, 3rd edition, Sage Publications, Londres, 2002, pp. 1-19. 
una dirección de correo electrónico. La submuestra finalmente obtenida estuvo conformada por un total de 17 personas, cuyas principales características se resumen a continuación (tabla 1):

Tabla 1: Características de la muestra cualitativa de víctimas $(\mathrm{n}=17)$

\begin{tabular}{ccccc}
\hline Identificador & Sexo & Edad & Provincia & Relación previa con el stalker \\
\hline 1 & Mujer & 19 & Barcelona & Amigo \\
\hline 2 & Mujer & 21 & Barcelona & Expareja \\
\hline 3 & Mujer & 19 & Barcelona & Compañero de estudios \\
\hline 4 & Hombre & 24 & Barcelona & Desconocido \\
\hline 5 & Mujer & 19 & Tarragona & Compañero de estudios \\
\hline 6 & Mujer & 19 & Barcelona & Miembro de la familia \\
\hline 7 & Hombre & 54 & Tarragona & Expareja \\
\hline 8 & Mujer & 20 & Barcelona & Desconocido \\
\hline 9 & Mujer & 20 & Girona & Conocido \\
\hline 10 & Mujer & 21 & Valencia & Compañero de estudios \\
\hline 11 & Mujer & 22 & Valencia & Compañero de estudios \\
\hline 12 & Hombre & 18 & Alicante & Amigo \\
\hline 13 & Mujer & 34 & Lleida & Conocido \\
\hline 14 & Mujer & 26 & Lleida & Desconocido \\
\hline 15 & Mujer & 19 & Tarragona & Conocido \\
\hline 16 & Mujer & 36 & Alicante & Desconocido \\
\hline 17 & Mujer & 24 & Valencia & Expareja \\
\hline
\end{tabular}

Junto a la de víctimas, se contó con una submuestra de profesionales, obtenida siguiendo un proceso de muestreo intencional, a partir de determinadas personas que trabajaban en el ámbito asistencial y en el sistema de justicia penal que previsiblemente hubiesen podido entrar en contacto con víctimas de stalking. Para ello se contactó con diversas instituciones con la finalidad de pedir la participación de profesionales que hubieran podido atender a este tipo de víctimas. Así, después de hablar con las personas responsables y de haber obtenido las correspondientes autorizaciones, nos fueron facilitados los datos de los profesionales dispuestos a participar en el estudio, que fueron contactados por vía telefónica o a través de correo electrónico. 
Esta submuestra estuvo finalmente formada por 27 profesionales, de los cuales 14 formaban parte del sistema de justicia penal $(51,9 \%)$-concretamente 6 eran agentes policiales, 3 fiscales, 2 jueces y 2 abogadas-, mientras 13 pertenecían al ámbito asistencial (48,1\%) -entre ellos, 8 psicólogos, 2 trabajadoras sociales y 1 educadora social pertenecientes a alguna de las Oficinas de Atención a las Víctimas del Delito (OAVD), a los Servicios de Intervención Especializada (SIE), a los Centros de Información y Atención a la Mujer (CIAD), a los Puntos de Información y Atención a la Mujer (PIAD) o a otros servicios de similar naturaleza-. Sus principales características se exponen en la tabla 2:

\section{b) Procedimiento}

Para la consecución de los objetivos marcados, decidieron realizarse entrevistas semi-estructuradas y en profundidad en las que se permitía a las personas entrevistadas relatar libremente su experiencia. Una vez terminada su exposición, se les realizaban preguntas conducentes a ahondar en aquellos temas que no habían aflorado de forma espontánea durante la entrevista. Respecto al instrumento empleado, se utilizaron tres modelos de entrevista distintos: uno destinado a víctimas, otro a profesionales que formaban parte del sistema de justicia penal y el tercero ideado para profesionales que trabajaban en el ámbito asistencial. Si bien los dos modelos diseñados para profesionales contaban con una parte común relativa al conocimiento del fenómeno y a la identificación de las víctimas, así como a la coordinación entre los diferentes órganos y a la respuesta adecuada a estas conductas, diferían en relación a las preguntas referidas al tipo de asistencia o protección ofrecida. El modelo de entrevista para víctimas estaba estructurado en tres partes, la primera dedicada a caracterizar la experiencia vivida, la segunda a identificar los principales efectos nocivos sufridos a raíz de la victimización y la última a conocer las estrategias de afrontamiento emprendidas por la víctima, incluyendo su posible interacción con el sistema de justicia penal y el grado de satisfacción con el mismo. 
Tabla 2: Características de la muestra cualitativa de profesionales $(n=27)$

\begin{tabular}{|c|c|c|c|c|c|c|c|}
\hline Identificador & Sexo & Antigüedad & $\begin{array}{c}\text { SJP/ } \\
\text { Asistencial* }\end{array}$ & Ocupación* & $\begin{array}{c}\text { Cargo/ } \\
\text { Institución* }\end{array}$ & Provincia & $\begin{array}{c}\text { Especialista } \\
\text { VG* }^{*}\end{array}$ \\
\hline 1 & Hombre & 6 años & SJP & $\begin{array}{c}\text { Sargento } \\
\text { GU }\end{array}$ & $\begin{array}{c}\text { Responsable } \\
\text { OAC }\end{array}$ & Lleida & No \\
\hline 2 & Mujer & 1 año & SJP & Letrada & $\begin{array}{l}\text { Responsable } \\
\text { turno oficio }\end{array}$ & Lleida & Sí \\
\hline 3 & Mujer & 6 años & Asistencial & Psicóloga & $\begin{array}{l}\text { Centro de } \\
\text { recursos } \\
\text { juveniles }\end{array}$ & Lleida & No \\
\hline 4 & Mujer & 8 años & Asistencial & Psicóloga & SAP Universidad & Lleida & No \\
\hline 5 & Mujer & No consta & SJP & Magistrada & $\begin{array}{l}\text { Audiencia } \\
\text { Provincial }\end{array}$ & Lleida & No \\
\hline 6 & Hombre & 18 años & Asistencial & Psicólogo & Técnico OAVD & Girona & No \\
\hline 7 & Mujer & No consta & Asistencial & Psicóloga & Técnica OAVD & Lleida & No \\
\hline 8 & Mujer & No consta & Asistencial & Psicóloga & Técnica CIAD & Lleida & Sí \\
\hline 9 & Mujer & No consta & SJP & Letrada & Técnica SIE & Tarragona & Sí \\
\hline 10 & Mujer & No consta & Asistencial & $\begin{array}{c}\text { Educadora } \\
\text { social }\end{array}$ & Técnica SIE & Tarragona & Sí \\
\hline 11 & Mujer & No consta & Asistencial & Psicóloga & Técnica SIE & Tarragona & Sí \\
\hline 12 & Mujer & No consta & Asistencial & Psicóloga & Técnica OAVD & Barcelona & No \\
\hline 13 & Mujer & 13 años & SJP & Fiscal & $\begin{array}{c}\text { Fiscal delegada } \\
\text { VG } \\
\end{array}$ & Lleida & Sí \\
\hline 14 & Mujer & 11 años & Asistencial & Psicóloga & $\begin{array}{c}\text { Coordinadora } \\
\text { PIAD }\end{array}$ & Barcelona & Sí \\
\hline 15 & Mujer & 12 años & Asistencial & Filosofa & Técnica PIAD & Barcelona & Sí \\
\hline 16 & Mujer & No consta & Asistencial & No consta & Directora SIE & Lleida & Sí \\
\hline 17 & Mujer & 1 año & Asistencial & $\begin{array}{c}\text { Trabajadora } \\
\text { social }\end{array}$ & Técnica SIE & Lleida & Sí \\
\hline 18 & Hombre & No consta & SJP & Fiscal & $\begin{array}{c}\text { Fiscal delegado } \\
\text { VG }\end{array}$ & Tarragona & Sí \\
\hline 19 & Mujer & 9 años & Asistencial & $\begin{array}{c}\text { Trabajadora } \\
\text { social }\end{array}$ & Técnica OAVD & Tarragona & No \\
\hline 20 & Mujer & No consta & SJP & Fiscal & $\begin{array}{c}\text { Fiscal delegada } \\
\text { VG } \\
\end{array}$ & Barcelona & Sí \\
\hline 21 & Hombre & 16 años & SJP & $\begin{array}{l}\text { Subdirector } \\
\text { MMEE }\end{array}$ & $\begin{array}{c}\text { Responsable } \\
\text { URPAC }\end{array}$ & Lleida & No \\
\hline 22 & Mujer & 17 años & SJP & $\begin{array}{l}\text { Agente } \\
\text { MMEE }\end{array}$ & Miembro GAV & Lleida & No \\
\hline 23 & Hombre & 10 años & SJP & $\begin{array}{l}\text { Agente } \\
\text { MMEE }\end{array}$ & $\begin{array}{c}\text { Responsable } \\
\text { GAV }\end{array}$ & Barcelona & No \\
\hline 24 & Hombre & 14 años & SJP & $\begin{array}{l}\text { Agente } \\
\text { MMEE }\end{array}$ & Miembro GAV & Tarragona & No \\
\hline 25 & Hombre & 9 años & SJP & Magistrado & JVM & Barcelona & Sí \\
\hline 26 & Mujer & 5 años & SJP & $\begin{array}{l}\text { Agente } \\
\text { MMEE }\end{array}$ & Miembro GRAV & Barcelona & No \\
\hline 27 & Mujer & No consta & SJP & Magistrada & JVM & Barcelona & Sí \\
\hline
\end{tabular}

*CIAD = Centre d'Informació i Atenció a la Dona; GAV = Grupo de Atención a la Víctima; GRAV = Grupo Regional de Atención a la Víctima; GU = Guardia Urbana; JVM = Juzgado de Violencia sobre la Mujer; MMEE = Mossos d'Esquadra; OAC = Oficina de Atención al Ciudadano; OAVD = Oficina de Atención a la Víctima del Delito; PIAD = Punt d'Informació i Atenció a la Dona; SAP Universidad $=$ Servicio de Atención Psicológica de la Universidad; SIE = Servicio de Intervención Especializada; SPJ = Sistema de justicia penal $/$ Asistencial $=$ Ámbito asistencial; URPAC $=$ Unidad Regional de Proximidad y Atención al Ciudadano; VG = Violencia de Género. 
Las entrevistas se realizaron entre mayo de 2015 y julio de 2016. Fueron grabadas y completamente transcritas con permiso explícito tanto de víctimas como de profesionales. El contenido de las mismas fue analizado empleando la metodología del análisis temático, sistematizando y transformando los datos originales en categorías más abstractas, que fueron finalmente codificadas $^{14}$.

\section{Resultados}

\subsection{Necesidades de protección de las víctimas y moti- vos para no denunciar los hechos}

Siguiendo la estela de algunos estudios emprendidos con anterioridad, el aquí realizado se centró en analizar cuáles eran las principales necesidades de tutela de las víctimas de stalking. Como ya habían puesto de manifiesto anteriores estudios ${ }^{15}$, preguntadas por tal aspecto, las víctimas apuntaron que su mayor demanda era dejar de ser objeto de atención insistente por parte del ofensor. Junto a ello referían que, en caso de que acabara por sustanciarse un proceso penal, preferían la protección al castigo del stalker:

E1: "Creo que lo que me hubiera gustado es que entendiera que yo no quería nada con él y que dejara de tener esta actitud conmigo (...). No creo que el castigo hubiera aportado nada. Creo que lo que se tenía que hacer es hacerle entrar en razón."

E10: "Definitivamente una medida (de protección). Una pena le tocaría el bolsillo y no le haría nada. Realmente una pena pecuniaria (...) a lo mejor me puede beneficiar en algún momento, como cumplir un capricho, pero una medida de protección hubiera sido mejor."

14 Vid. Braun, V. / Clarke, V.: «Using Thematic analysis in Psychology», en Qualitative Research in Psychology, vol. 3, n 2, 2006, pp. 77-101.

15 Vid. Korkodeilou, J.: «Dealing with the unknown: Learning from stalking victims' experiences», op. cit., pp. 261-266. 
E14: "Sin duda me quedaría con la protección o mejor aún la vigilancia del individuo identificado. Imponer una pena o el proceso penal tradicional implicaría perder mi anonimato y si recibe un castigo por simplemente seguirme creo que aumentarían sus pensamientos hacia mi persona y seguramente de una forma negativa pudiendo provocar venganza."

E17: "Medidas para protegerme de él. No tengo especial interés en que se le condene, solamente quiero estar tranquila de él."

En contra de lo que constituyó la tónica general, una sola víctima prefirió el castigo de la ofensora frente a su propia protección, como se deduce de sus palabras:

E11: "A ella en concreto, a la que indujo a la conducta de todas, que se la condenase porque es mala. Porque sé que se lo va a hacer a más gente."

Pese al deseo de poner fin a la situación de acoso y obtener protección por parte del sistema de justicia penal, únicamente 3 de las 17 personas entrevistadas pusieron los hechos en conocimiento de la policía, en concordancia con el bajo porcentaje de denuncia revelado en las encuestas de victimización ${ }^{16}$. Fue precisamente esta reducida tasa de denuncia la que determinó que decidiéramos preguntar a las víctimas cuáles habían sido los motivos que las habían llevado a no denunciar los hechos. Entre estos, como ya habían apuntado otros estudios ${ }^{17}$, se encontraban la ausencia de pruebas, el miedo a represalias, la falta de voluntad de castigar al ofensor, el hecho de considerar que era un tema

16 Vid. FRA - European Union Agency for Fundamental Rights: Violence against women: an EU-wide survey. Main results, op. cit., p. 91; Bodelon, E. / Igareda, N. / Casas, G.: Violencia sexual, acoso y miedo al delito. Informe Español, op. cit., pp. 19-20 y Villacampa Estiarte, C. / Pujols PÉrez, A.: «Stalking: efectos en las víctimas, estrategias de afrontamiento y propuestas legislativas derivadas», op. cit., pp. 22-24.

17 Vid. Acquadro, M. / Varetto, A.: «Motives to Report Stalking to the Police: A Comparison Between a Large City and a Small Town in Italy», en Journal of Aggresion, Maltreatment and Trauma, vol. 26, 2017, pp. 515 y ss. 
privado o que no era lo suficientemente grave para ser denunciado, así como la falta de confianza en la efectividad del sistema de justicia penal e incluso el temor a la victimización secundaria. En este sentido, las personas entrevistadas manifestaron:

E4: "Mi madre era de solucionarlo por vía legal (...). A ver, mi madre se enteró (...) y me dijo que tenía que ir a la policía pero no sé, yo no lo veía factible porque, vamos a ver, piense que soy de (una ciudad pequeña) y entonces claro ahí nos conocemos todos, los policías incluso. Es como que me da un poco de cosa. O sea, ¿qué voy a hacer? ¿Presentarme en la policía y decir que hay un "mariquita" que me está acosando? (...). A mí por ejemplo el tema de acudir a la policía no me parecía lo más factible. (...). Vale, el tío a lo mejor puede cumplir, yo que sé, 2 años (...) pero ¿y luego qué? O sea, al fin y al cabo la putada ya está hecha. (...) Al margen de la intervención policial o judicial. En estos casos no creo en la efectividad."

E5: "Mi padre habló con el policía y todo pero claro el policía dijo: «yo no puedo hacer nada si ustedes no denuncian» ¿sabes? Teníamos que tomar ya unas medidas y le dije que no a mi padre, que no quería más follones (...). No me hubiera hecho bien ni a mí ni a ellos. No hubiera servido de nada."

E7: "Puedes decir voy a la policía, pero yo intuía que el camino de la vía directa era problemático precisamente porque acudiría a encontrar, no a ella, sino a su entorno, hermanos, padre, madre que me acusaran o que ella hubiera dado una información para acabar conmigo, para decirlo de alguna manera y que esto pudiera provocar problemas más grandes: que me dieran una paliza, que nos enfrentáramos, que hubiera violencia... Y esto hizo que me mantuviera un poco sin saber qué hacer (...). La situación psíquica, el estado psíquico de esta persona hubiera tirado cualquier procedimiento por el suelo. Hubiera aportado un peritaje psiquiátrico o psicológico que hubiera atenuado la pena (...) y ¿qué? ahora la tendrás que ver en un juzgado con su hermana, su padre, sus amigos... probablemente me volverá a insultar en el juzgado... Si vas allí tú ya sabes qué es esto, si has ido a algún juicio... no habrán amenazas pero sí que me volverán a insultar o a mirar mal... pueden buscar represalias. $\mathrm{Si}$ es condenada o le ponen una multa o lo que sea no creo que 
la cosa quede bien. Como está loca, como es una desequilibrada probablemente tendría una atenuante (...). Se hubiera buscado la vida y esto hubiera acabado en 6 meses de prisión y 6 meses de prisión ni ingresas ni constan ni nada, una multa que a mí tampoco me decía nada (...). Pregunté a un abogado y le dije si esto era conveniente denunciarlo y tal y me dijo: «mira, probablemente esta mujer está mal de la cabeza, padece algún tipo de depresión o esta enganchada a alguna droga, probamente esto al final del final no prosperaría en nada porque tendría atenuantes y eximentes pues... yo que sé, de alcoholismo, de adicción a las drogas $(\ldots)$. Por tanto estaremos años teniendo que ir a un juzgado, teniendo que declarar... tú tendrás que asumir los gastos de un abogado, de un procurador....». Dice: «hagamos una cosa, intentemos no darle ninguna importancia y simplemente continúa con tu vida normalmente (...). No tendrás que tener pleitos ni verte las caras con ella, con su familia»."

E8: "Porque cuando me decidí a hablar con él ya se acabó y ya no valía la pena (se refiere a denunciar los hechos) (...). Sólo quería que me dejara tranquila."

E9: "Por falta de pruebas no pudimos hacer nada porque en el momento de los hechos estábamos él y yo solos. Y como en el tema del acoso es más lo que tú puedas sentir que lo que pueda haber... Porque yo me sentí en aquel momento agredida pero no hay pruebas de nada, decidí no denunciar. (...) Para perder el tiempo y tener que recordarlo todo y pasarlo mal por una cosa que no va a ningún sitio no lo hubiera hecho (se refiere a denunciarlo)."

E11: "Yo al final decidí no denunciar. Mi madre quería denunciar, pero yo le dije que no quería (...). Me daba miedo denunciarlas por lo que pudieran hacer, o por si acaso el delito no era para tanto."

E16: "Pero, ¿cómo querías que lo denunciara? No me había hecho nada. Es que en ningún momento me planteé denunciarlo porque él nunca me dijo nada. Si me hubiera intimidado...pero es que parecía que era todo cosa mía. Porque él también podía decir: «yo no te seguía, venía hacia aquí» (...). Yo quería que me dejara tranquila y me olvidara y se fuera y no volverlo a ver nunca más, ni en el juzgado ni en ningún sitio.” 


\subsection{Conocimiento del fenómeno de stalking por parte de los profesionales}

Dado que el segundo objetivo de la investigación consistía en analizar el tratamiento institucional ofrecido a estos casos comenzando por valorar el conocimiento que los profesionales tenían respecto del stalking, los aspectos inicialmente abordados en las entrevistas giraron en torno a esta cuestión. Concretamente, se realizaron preguntas dirigidas a averiguar, en primer lugar, el conocimiento del fenómeno en general; en segundo lugar, el grado de conocimiento de los mecanismos legales existentes para proteger a las víctimas; $y$, en tercer lugar, el nivel de información y/o formación recibida en torno a este tipo de victimización. Por último, se pidió a los entrevistados que realizaran una valoración sobre la suficiencia de su conocimiento sobre esta realidad.

\section{a) Conocimiento del fenómeno en general}

Comenzando por la primera de las cuestiones abordadas, el conocimiento del fenómeno de stalking en general y, más concretamente, por la conceptuación del mismo, cabe indicar que uno solo de los profesionales entrevistados reconoció abiertamente desconocer qué era el acoso predatorio $(n=1 ; 3,7 \%)$, si bien entre las personas que dijeron conocer esta realidad se ofrecieron distintas visiones de la misma que no siempre se adecuaban a la conceptuación del fenómeno propia de la doctrina ${ }^{18}$, cosa que confirmaría lo ya apuntado por otros estudios ${ }^{19}$. Así, un primer grupo de profesionales $(n=8 ; 29,6 \%)$ conformado únicamente por personas provenientes del sistema de justicia penal caracterizaron el fenómeno exclusivamente en base a la definición legal del mismo, sin ofrecer una concepción más personal

18 Vid. Villacampa Estiarte, C.: Stalking y derecho penal. Relevancia jurídico-penal de una nueva forma de acoso, Iustel, Madrid, 2009, pp. 41-42.

19 Vid. Farrell, G. / Weisburg, D. / Wyckoff, L.: «Survey results suggest need for stalking training», en The Police Chief, vol. 67, nº10, 2000, pp. 162-167. 
del mismo que denotase un proceso de reflexión conducente a una identificación de su esencia más allá de lo tipificado por el Código Penal. Un claro ejemplo de este apego al concepto legal del stalking puede hallarse en el siguiente fragmento:

E20: "Pues lo que dice el Código. (...) No puedo darle ningún dato más, ninguna opinión sobre lo que hace un legislador. Para mí el acoso es el delito que refleja el Código Penal en la reforma y con la entrada en vigor a partir del 1 de julio del año 2015. Y lo que establece aquí: una actitud continuada de llamadas telefónicas, seguimientos, contactos incluso a través de terceros para variar o intentar conseguir que una persona pues imponerle tu presencia. Esto es el acoso."

Sin embargo, un segundo grupo de profesionales apostaron por exponernos definiciones de elaboración propia, al margen de la concepción creada normativamente $(n=19 ; 70,4 \%)$. Entre las conceptuaciones acuñadas por este segundo grupo, la que afloró en mayor medida $(n=10 ; 37 \%)$ fue la que identificaba de forma exclusiva el acoso predatorio como una manifestación de la violencia doméstica y/o de género, conforme a lo apuntado investigaciones previas ${ }^{20}$. $\mathrm{Al}$ respecto, no pudieron establecerse diferencias entre los profesionales provenientes del ámbito asistencial y del sistema de justicia penal, pues esta tendencia se hizo patente en ambos grupos. Así, en las entrevistas se ofrecieron definiciones como:

E6: "El concepto que tengo es este concepto de persecución y acoso en principio en el campo de la violencia de género. Del hombre hacia la mujer, habitualmente cuando se ha producido una relación previa incluso sin convivencia de pareja."

E14: "El stalking yo lo entiendo como cualquier forma de acoso hacia una mujer, de las diferentes maneras que puede haber."

E22: "Bueno, es acoso dentro de la familia."

20 Vid. Morris, S. / Anderson, S. / Murray, L.: Stalking and Harassment in Scotland, op. cit., pp. 43 y ss. 
E26: "Es otra manera de imposición, de control sobre la mujer, de violencia de género o de violencia doméstica si es sobre el hombre."

Junto a lo apuntado, no fueron pocas las personas que identificaron el fenómeno como una específica estrategia de control sobre la víctima en el marco de una situación de desigualdad entre víctima y victimario, comúnmente en los contextos de violencia de género y/o violencia doméstica antes apuntados $(n=8 ; 29,6 \%)$. Al respecto, algunos de estos profesionales nos exponían:

E8: "Para mí es querer controlar a la otra persona mediante la lejanía. No me acerco, con cierta distancia, pero que sepas que estoy aquí controlándote. Es ejercer un control sobre el otro con cierta distancia."

E16: "Este acoso está porque la violencia bebe del dominio y el control que quiere ejercer el hombre sobre la mujer, por tanto hay control telefónico, hay hombres que han dejado de trabajar para seguir a la mujer, mujeres que son acompañadas aquí y les decimos a ellos que no pueden entrar... hay este control y este acoso."

E21: "Para mí es una forma de intentar controlarlas, de intentar sacar de ellas alguna cuestión."

Los profesionales tendieron, además, a definir el stalking con base en su fenomenología, especialmente a través de las conductas en que puede concretarse el patrón acosador $(n=8$; $29,6 \%$ :

E7: "Entonces es esto, son llamadas telefónicas continuas, mensajes, acoso o cualquier otra cosa que pueda lesionar gravemente la libertad y el sentimiento de seguridad de la víctima aunque no se produzca violencia."

E24: "Se suele hacer de forma progresiva y empieza telefónicamente, vía llamadas o vía Whatsapps, después ya pasamos a redes sociales, y cuando la víctima tiende a cambiar de teléfono o bloquear o tal pues en los casos más graves este acoso se puede dar en el sitio de trabajo, en el domicilio, en persona, haciendo vigilancias con el vehículo..." 
Si bien con carácter minoritario $(n=2 ; 7,4 \%)$, la caracterización del fenómeno se realizó sobre la base de las consecuencias que este tiene para la víctima:

E9: "Básicamente es un acoso hacia la mujer de forma que le provoque que tenga que modificar todos sus hábitos cotidianos o le cause una angustia o le cause un desequilibro suficiente como para que a ella le afecte de forma emocional."

E25: "Es una situación de acoso que por su intensidad llega a perturbar la vida de la persona, (...) sobre todo a la afectación de la persona que no puede ser solo desde el punto de vista subjetivo, tiene que ser un elemento objetivo, una cierta entidad del comportamiento y la afectación a la vida de la persona."

Por último, 2 de las 27 personas entrevistadas $(7,4 \%)$ equipararon el stalking con una modalidad agravada de acoso. En este sentido, nos decían:

E1: "El stalking para mí es un acoso agravado."

E12: "Para mí es cuando es un acoso muy bestia, muy exagerado."

b) Conocimiento de los mecanismos legales existentes para proteger a las víctimas

En segundo lugar, en cuanto al conocimiento de los mecanismos legales de protección a las víctimas como un segundo aspecto mediante el que medir su grado de consciencia sobre estos procesos, 20 de los 27 entrevistados $(74,1 \%)$ tenían conocimiento de que, a raíz de la reforma del Código Penal de 2015, estas conductas habían adquirido relevancia penal específica. En concreto, todos los profesionales del sistema de justicia penal y prácticamente la mitad de los profesionales del ámbito asistencial -6 de los 13 entrevistados (46,2\%)- contaban con esta información. No obstante, el colectivo profesional en que más evidente fue la ausencia de conocimiento normativo fue en aquellos activos en el ámbito asistencial que no actuaban en oficinas de atención a la víctima, quizás porque su interacción 
con el sistema de justicia penal se producía de una forma más esporádica. Más allá de la consciencia sobre la específica criminalización de estas conductas, se preguntó a los profesionales si tenían conocimiento de la existencia de protocolos de actuación a seguir en caso de producirse. En este sentido, las 27 personas entrevistadas coincidieron en indicar que no existía un protocolo específico para los supuestos de stalking, pero que estaban familiarizadas con los existentes en materia de violencia de género. Al respecto, uno de los entrevistados, perteneciente al ámbito asistencial, apuntó también la posibilidad de aplicar a estos supuestos protocolos referidos a otras formas de la criminalidad que se hallan conexas al acoso predatorio:

E6: "No. Vaya conozco bastante todos los protocolos que hacen referencia a toda la temática de violencia de género y violencia doméstica y otras problemáticas que tocan el campo jurídico y no. Sobre estas en concreto no. Lo que pasa es que existen protocolos de violencia de género, incluso hay determinados protocolos para el tema de bullying que podrían aplicarse. Pero no, del stalking no."

\section{c) Nivel de formación y/o información recibida en torno a este tipo de victimización}

El tercer aspecto medido para determinar el grado de conocimiento del stalking por parte de los profesionales tiene que ver con formación recibida sobre el mismo, lo que reviste especial interés por considerarse que el hecho de tener conocimiento sobre el fenómeno llevaría a una mejor detección de las víctimas de este tipo de comportamientos. Preguntados los profesionales acerca de la formación recibida, se constató que ninguno de ellos había sido instruido de forma específica en relación con el acoso predatorio, si bien la mayoría reconocían tener una amplia formación en violencia de género $(n=17 ; 63 \%)$ o en atención a las víctimas en general $(n=4 ; 14,8 \%)$. Por otro lado, algunos de los entrevistados, mayoritariamente provenientes del ámbito policial, reconocieron haber recibido formación acerca del conjunto de modificaciones del Código Penal efectuadas por la LO 
1/2015, sin incidir de forma específica, sin embargo, en el delito de acoso $(n=7 ; 25,9 \%)$.

Por último, en referencia a la valoración sobre la suficiencia del conocimiento de esta realidad, cabe indicar que existió una gran disparidad entre los profesionales del ámbito asistencial y los del sistema de justicia penal en cuanto a la valoración que efectuaron de la formación recibida. Así, la práctica totalidad de profesionales pertenecientes a servicios asistenciales se mostraron muy críticos con su falta de formación $(n=11$; $40,7 \%)$ :

E6: "Hacemos formaciones donde se habla de violencia de género y de conductas, tipologías, etc. Pero no se hace una discriminación, una concreción sobre esta problemática y, es más, para hablar de violencia psicológica se pasa muy por encima, no se profundiza. Estas conductas sí que quedan reflejadas como posibles conductas del ofensor pero no se especifica sobre una etiqueta de nombre que da un marco. No se le da la importancia que tienen."

E8: "El ayuntamiento también hace formación propia sobre violencia machista y yo a parte pues también fuera pues si veo jornadas y cosas pero (...) propiamente del stalking nada. Pero creo que sería muy importante para detectarlo y ayudar a la mujer. Porque si no estás formado no lo ves, si no lo ves no existe y por tanto no puedes ayudar a esa persona. Porque tampoco la ayudarás a que ella tome consciencia. (...) Por tanto yo creo que es muy importante la formación a todos los niveles jurídico, a los cuerpos policiales, a los psicólogos... Muy importante."

En cambio, la mayoría de los profesionales adscritos al sistema de justicia penal $(n=9 ; 33,3 \%)$, especialmente aquellos pertenecientes a la carrera fiscal y judicial, se mostraron más autocomplacientes con este aspecto:

E20: "Hombre yo creo que somos fiscales, ya tenemos la formación. La Fiscalía General del Estado siempre prepara cursos para esto, pero realmente se nos supone la formación, ¿eh? Cuando cambian una ley los fiscales la estudiamos. Se supone que, siendo juristas, tenemos que entender el delito. Es como 
decirle a un médico si sabe operar, hombre se le presupone, ¿no? Formación siempre hay, la Fiscalía General del Estado tiene sus cursos de formación en la que se habla de este delito y de todos los demás delitos. Pero vaya una formación específica para abordar este delito no. Que yo sepa vaya, en mi caso no porque no la creo necesaria."

E25: “ $-¿$ Cree que sería conveniente que se les ofreciera formación sobre el fenómeno?

-Tampoco sé si es... hombre, todo lo que sea formación siempre viene bien, pero tampoco creo que sea la mayor carencia que tengamos los jueces."

\subsection{Detección de las víctimas por parte de los profe- sionales: la exclusiva vinculación del stalking con la violencia de género en el ámbito de la pareja}

Junto al conocimiento de estos procesos por parte de los profesionales, un segundo aspecto abordado para analizar el tratamiento institucional ofrecido a las víctimas consistió en conocer la fenomenología de los casos de stalking que accedían a los distintos servicios para determinar la facilidad con que los profesionales las detectaban ${ }^{21}$. En este sentido, de las entrevistas realizadas con profesionales puede colegirse rápidamente que existe una práctica ausencia de detección de víctimas de acoso que no hayan padecido, de forma previa o coetánea a la conducta acosadora, violencia física o psicológica por parte de su pareja o expareja $^{22}$. De las entrevistas se deducen además tres elementos

21 En este sentido, algunos de los estudios cualitativos realizados con profesionales revelaban ya la existencia de dificultades en lo que se refería a la identificación del fenómeno de stalking. Vid. Klein, A. / Salomon, A. / Huntington, N. / Dubois, J. / LAng, D.: A Statewide Study of Stalking and Its Criminal Justice Response, NCJ Publication \# 228354, op. cit., pp. 27-40.

22 Destacando, a este respecto, que pese a que la definición del acoso por parte de los profesionales se vinculaba también con carácter general a la violencia doméstica, ninguno de los casos aflorados en las entrevistas se dio en un contexto que, habiéndose producido en el ámbito doméstico, no proviniera de relaciones sentimentales. 
que pueden estar contribuyendo a la invisibilización del patrón acosador cuando es realizado en ámbitos relacionales distintos al sentimental.

En primer lugar, una de las razones que pueden explicar esta ausencia de detección del acoso fuera del ámbito de la violencia en la pareja tiene que ver con la escasa auto-consciencia de las propias víctimas sobre el padecimiento de estas conductas delictivas, cosa que ha sido ya puesta de manifiesto por otras investigaciones realizadas con víctimas ${ }^{23}$, pero que constituyó también la conclusión a la que llegaron algunos de los profesionales aquí entrevistados. Así puede deducirse de los fragmentos de entrevistas transcritos a continuación:

E8: "Es que yo creo que es un fenómeno que no se detecta como violencia y entonces quizás la mujer no va al servicio a pedir ayuda porque ¿en qué me ayudaran, no? Quizás es por eso. No quiere decir que no haya, sino que la violencia de género ya está muy difundida, las mujeres estamos muy concienciadas de lo que es, de que tenemos que decirlo, de que tenemos que denunciarlo, pero la violencia en el ámbito laboral o en el ámbito comunitario, que un vecino o un desconocido... Yo creo que aún no está suficientemente sensibilizada la sociedad para hacer este paso de me tengo que informar o lo tengo que denunciar."

E9: “A veces la mujer no lo reconoce como violencia esto. Esto lo detectan servicios que ya tienen más formación o ya están más acostumbrados a detectar y son los que normalmente nos las derivan."

E11: "Para ellas es difícil poder identificar lo que es un buen o un mal trato y, por otro lado, aquello cultural, lo que nos han hecho entender qué es ser mujer y qué es ser hombre. Somos las fuertes, las que aguantamos. Lo social, lo construido, aquello con lo que nos identificamos como mujeres pero que no es real, es construido, también influye."

23 Vid. Villacampa Estiarte, C. / Pujols Pérez, A.: «Prevalencia y dinámica de la victimización por stalking en población universitaria», op. cit., pp. 9-10. 
E21: "También piensa que nos llegan pocas denuncias con relación a la realidad. Y quizás los hombres son muy reticentes a denunciar porque si ya les cuesta a las mujeres pues a los hombres también les cuesta mucho denunciar. Alguno quizás hay pero lo desconocemos. La inmensa mayoría están relacionados con la violencia de género."

En segundo lugar, la ya constatada falta de formación sobre este fenómeno por parte de los profesionales unida a su amplia formación en violencia de género circunscrita al ámbito de la pareja se observa como induce a la identificación entre ambos fenómenos, de manera que el stalking es concebido por ellos como una parte integrante de este tipo de violencia. En concreto, 21 de los 27 profesionales $(77,8 \%)$ indicaron, de entrada, que el acoso predatorio era una cuestión exclusiva de violencia de género:

E6: "No me consta que hayamos visto ninguna situación que no fuera de relación de pareja."

E7: "Es violencia de género, como amigos y así no entraría como stalking."

E8: "Se considera violencia machista. Y antes quizá es un stalking más sutil, es que me preocupo por ti, dónde has ido... más sutil pero que es igualmente un control y un hostigamiento y un acoso. Sí que hemos visto violencia familiar de hijos a padres pero no se da el stalking. Y algún caso suelto de violencia en el ámbito laboral pero es más acoso sexual. Stalking en el ámbito que no sea de pareja no."

E26: "Cuando hay un acoso de este tipo ya no es solo el acoso, es un puntito más dentro de otros conflictos que se generan ya sea maltrato físico, abuso sexual.... Y entonces este acoso está dentro, cabe dentro. (...) Sí que va asociado a la violencia de género, porque es parte de este control que ejerce el hombre sobre la mujer".

En tercer lugar, los perfiles que los profesionales manejan de víctima y ofensor de stalking se identifican con los propios de estas figuras en los supuestos de violencia familiar. La 
imagen de la víctima de los entrevistados -en 20 de los 27 casos (74\%) - se correspondía con una mujer que había sido previamente victimizada por su pareja o expareja hombre. Asimismo, el estereotipo creado para el ofensor coincidía con el hombre maltratador, en algunos casos incluso relacionándolo con adicciones al alcohol o a las drogas y con un bajo nivel sociocultural $(n=3 ; 11,1 \%)$. Así, algunos de los profesionales exponían:

E1: "La mayor parte de las denuncias suelen ser de familias desestructuradas o de familias que ya tienen de antes antecedentes de lesiones o de amenazas anteriores (...). Ya ves que normalmente son gente sin cultura (...). Normalmente son personas con una cierta clase social, o con varios antecedentes penales como peleas en el bar. (...) Casi todas te explican lo mismo, que bien bebe o que toma drogas, o bien que llega a las tantas de la mañana, o que normalmente es violento (...). La mayor parte de las víctimas mujeres que vienen a denunciar nos explican que se están separando y que han discutido y que le ha dado algún golpe, o bien que han discutido por los niños, o por términos de la separación."

E16: "Son mujeres las que lo padecen que hasta el momento había sido la víctima perfecta dentro de la relación, entre comillas, y pensaba que la tendría allí para siempre. Y el hecho de que ella se haya hecho fuerte y haya decidido romper la relación pues esto es algo que él no puede aceptar. (...) La sensación de poder que tienen los hombres de yo puedo ser agresivo, yo tengo el poder, yo lo puedo demostrar porque se me permite y lo puedo hacer como hombre. Yo creo que está ligado con la masculinidad."

E22: "La mayor parte han sido mujeres agredidas por hombres, eran sus parejas."

Junto a los supuestos en que el stalking directamente no se identifica, en los casos en que sí se detecta queda a menudo enmascarado por el conjunto de conductas que se generan en la situación de violencia, sin que sea denunciado ni tratado de forma específica. Así, los profesionales señalaron no haberlo reconocido como un fenómeno autónomo a pesar de que apareció en 
los relatos en que las víctimas les exponían la situación global de violencia. Resulta habitual, en este sentido, que en las entrevistas aflore una diferenciación entre 2 tipos de stalking: lo que los profesionales denominan como «stalking puro»-es decir, aquellas conductas de acoso predatorio que no siguen o conviven con otros tipos de violencia dentro de la pareja- y el apodado «stalking mixto»-entendido como estrategia de control enmarcada en una atmósfera de violencia física y/o psicológica más amplia-. Aclarando, en este sentido, que el «stalking puro», no resulta habitual en la práctica profesional:

E7: "Mixto hay más. Solo puro, única y exclusivamente, no hay tantos. A veces puede ser un quebrantamiento, puede ser agresión física más acoso y después hay un quebrantamiento que es stalking. Puede ser. Ahora, única y exclusivamente, no sé. El fenómeno solo no se ve mucho, pero con maltrato físico como más de obsesividad, de control sí, de con quién vas, dónde vas y así."

E15: "No recuerdo ningún caso en que no haya habido violencia al menos psicológica previamente dentro de la pareja (...). Normalmente es una continuidad."

E21: "El acoso yo lo considero como una dimensión. En muchos casos hay una dimensión de este tipo de acoso, lo encontramos en formas más claras y en otras más sutiles. No sé si el hecho de la pureza con la que pudiéramos decir que todas las características. En muchos de estos expedientes hay características que tienen que ver con este control que el hombre ejerce sobre la mujer y que tiene diferentes connotaciones. En un 50\% se encontraría alguna característica del stalking. Un stalking puro no lo recuerdo ahora."

E24: "El acoso no viene nunca solo. Estaría mezclado con otros tipos de maltrato que estarían las tipificaciones mezcladas. Yo un atestado que haya tipificado solo como acoso no lo he visto nunca desde la nueva modificación. Solo con esta tipificación ¿eh? Siempre van acompañados de otros hechos."

E25: "Casi lo veríamos, si hay una violencia habitual, como un indicio más, pero como un hecho autónomo no creo que los fiscales... No me lo había planteado." 


\subsection{Valoración de la respuesta normativa al stalking: tratamiento sustantivo-penal del fenómeno}

En relación con el tercer objetivo de la investigación, relativo a conocer la valoración que los profesionales y victimas efectuaban de la respuesta jurídica ofrecida al stalking, comenzando por la valoración que les merecía a los profesionales la regulación jurídico-penal de estas conductas a partir de la reforma del Código Penal de 2015, cabe indicar que todos los entrevistados valoraron positivamente su criminalización específica $(n=27 ; 100 \%)$, especialmente en punto a visibilizar el fenómeno:

E7: "Es dar luz a una cosa que ya existía pero que ahora es visible. A mí me parece bien en este caso."

E9: "Creo que se le ha visibilizado más, era un delito que estaba escondido y no se veía. Ahora se ha visibilizado más, ahora con la nueva redacción es más fácil de detectar."

E15: "A mí me parece muy necesario porque quedaba muy invisibilizado. Siendo una parte tan importante quedaba muy invisibilizado."

Con el propósito de abordar la cuestión con una mayor profundidad, se preguntó a los encuestados si con anterioridad a la reforma del Código Penal habían detectado dificultades para incriminar conductas propias del acoso predatorio. En este sentido, los profesionales apuntaron que eran escasos los supuestos en los que había resultado imposible dar una respuesta penal al stalking con anterioridad a su tipificación específica, puesto que en la mayor parte de supuestos estas conductas, pese a no ganar relevancia penal por sí mismas, se daban de forma conjunta con otros comportamientos que sí eran merecedores de respuesta penal:

E24: "Comentaba antes que estas actitudes se vienen dando desde hace tiempo, antes teníamos que entrar en otras calificaciones a nivel técnico nuestro, pero normalmente estas actitudes no iban solas sino que iban acompañadas de insultos, amenazas, coacciones o agresiones. Se tipificaban estas cosas más concretas." 
E25: "Pocos porque es difícil que se den supuestos de stalking en que no haya ningún otro delito, hablo de la regulación anterior, era difícil que alguien que acosaba no acabara insultando, amenazando... Lo que era el acoso sin cometer ningún otro delito se nos daba pocas veces"

No obstante, la mayoría de los profesionales provenientes del sistema de justicia penal $(n=12 ; 44,4 \%)$ reconocieron que los supuestos de stalking en que no se producían de forma conjunta otras conductas penalmente perseguibles no hallaban un buen acomodo ni en el delito de coacciones ni en el de amenazas, a los que hasta la específica criminalización de estas conductas se había venido reconduciendo con carácter general este patrón conductual:

E1: "No podíamos tipificarlo completamente como una coacción. Porque la coacción debía de implicar que realizaras algún tipo de acto que implicara que estuvieras coaccionado. Pero si no hacías nada más, teníamos un problema. Y es que, claro, con la coacción lo que teníamos es que a mí me habían coaccionado, y entonces implica hacer una conducta diferente. Vale, perfecto. ¿Pero y si no la hay? Claro, entonces implica que no hay cambio de conducta y por tanto, no hay coacción. Por tanto, no te he intimidado suficiente para que tengas que adoptar otra conducta."

E2: "Una amenaza es diferente de una persecución o un acoso de esta manera. Ya que te pueden amenazar sin que te acosen de dicha manera. Y es que solamente era calificable como amenaza."

E13: "Siempre parecía que se nos quedaba un poco corto con las coacciones pero claro era la figura como más parecida que podía haber a la regulación que ahora se hace del acoso. Pero bueno siempre es mejor que haya una especificación en la tipificación penal como en este caso."

E18: "Los jueces sí que eran muy reacios a aplicar el delito de coacciones porque el delito de coacciones implica una intimidación, implica una violencia (...). Va un poco en este sentido. Yo no voy a aplicar este delito de coacciones porque esta 
intimación o esta violencia no llega a integrarla efectivamente y por el principio de legalidad no voy a extender, digamos, analógicamente el delito de coacciones a este supuesto porque no está contemplado. Y esto es lo que viene a resolver este artículo. Entonces a partir de ahora para nosotros es mucho más sencillo (...) porque antes sí podía haber condenas pero no era suficiente ese... O había la condena del penal pero las audiencias, claro, decían que no podía extenderse analógicamente el delito de coacciones. Ahora lo tenemos mucho más sencillo porque al tipificarse específicamente sí que ya lo metemos ahí y yo creo que habrá muchas más condenas porque, claro, ya está expresamente tipificado. Que son molestas y que no adquirían relevancia penal con el delito de coacciones ya lo metemos aquí y para nosotros es mucho más sencillo."

E25: "Yo entendía que no era delito, que no entraba dentro del delito de coacciones porque en las coacciones hace falta violencia y por tanto los acababa archivando pero me creaba un cierto malestar porque veía que hacía falta una respuesta."

En sentido contrario, una de las magistradas entrevistadas $(3,7 \%)$ consideró que, a pesar de que la introducción del nuevo tipo penal resulta positiva en atención a la visibilización del fenómeno -a modo de derecho penal simbólico-, ya existían tipos penales a los que podían reconducirse estas conductas, siendo el tipo paradigmático el de las coacciones:

E27: "Desde mi punto de vista había instrumentos para castigar ya estas conductas antes en el Código Penal y a veces con la introducción de otras nuevas tipologías penales nos encontramos que no responde a las expectativas que se habían generado con un nuevo tipo penal. (...) Entonces por eso digo que va a ser complicado y que desde mi punto de vista no introduce demasiadas novaciones dentro del Código Penal porque hasta ese momento había instrumentos para poder castigarla y, por tanto, yo creo que no va a responder a las expectativas que se han generado con esta inclusión. (...) Porque, a ver, el acoso tal cual lo define el 172 ter $\mathrm{CP}$ yo creo que es reconducible a coacciones. (...) Creo que había instrumentos en el Código Penal para condenar estas conductas. (...) No digo yo que sea perfecto el ordenamiento jurídico, lo que digo es que a veces con las 
reformas lo estropeamos y dificultamos tanto la investigación del delito como el enjuiciamiento del delito."

Abundando en la cuestión de la incriminación de estas conductas, se preguntó a los operadores jurídicos entrevistados qué problemáticas consideraban que podía tener la nueva tipificación. Al respecto, uno de los puntos más controvertidos fue la falta de determinación del resultado típico del delito, que fue apuntado por 4 de los 14 profesionales del sistema de justicia penal entrevistados $(28,6 \%)$ :

E2: "El problema está en determinar hasta qué momento se entiende como acoso, y en qué momento no lo es. ¿Cuántas llamadas se puede considerar que es un caso de acoso y de cuántas no lo serían?"

E18: "El tipo pide una alteración grave del desarrollo de la vida cotidiana de la víctima, que a una persona en la vida cotidiana pues de una forma grave la alteres. Yo creo que depende de las conductas, por ejemplo el llamar continuamente a una persona, si solo es eso, yo creo que no entraría dentro del tipo. Y de hecho muchas audiencias lo venían apuntando un poco así. (...) El fiscal ve que hay 359 llamadas, que es una molestia, que es una molestia muy grande y que una persona se puede sentir incluso peor que otra persona que le estén siguiendo por la calle, pero claro, a lo mejor no llega a ese alterar gravemente la vida cotidiana (...). Yo creo que en este caso no tendría relevancia penal."

E27: "La redacción del tipo es un poco... siempre y cuando se altere gravemente... claro, es un elemento muy subjetivo la alteración grave."

Finalmente, se hizo hincapié en la confusa redacción del artículo, que a juicio de los entrevistados dificulta la aplicación del tipo penal:

E13: "A veces te da un poco la sensación de que es un poco cajón de sastre. Los artículos cuanto más cortos son en penal más concretos son. Cuando lo alargas mucho te queda un poco la sensación de que se convierte en cajón de sastre. Es un delito 
que recoge muchas conductas. ¿Sabes qué ocurre? Que me genera confusión, porque la regulación de violencia antes... el articulo 153 y el articulo 171 solo son para víctimas de violencia de género. En cambio en esta reforma se regulan en el mismo artículo todo tipo de víctimas. Lo tienes que leer con mucho ojo para no confundirte y ver qué tipo de personas están metidas en uno u otro. Esto también nos está dando muchos problemas para determinar cuándo es necesaria la denuncia o no para poder continuar con el procedimiento, te lo dice aquí pero aquí te pone la regla general."

\subsection{Valoración de la respuesta normativa al stalking: tratamiento institucional prestado a las víctimas, medidas de protección ofrecidas y problemática conexa a su consecución}

Dentro del tercer objetivo de la investigación, consistente en conocer la valoración que los colectivos entrevistados efectuaban de los mecanismos legales de respuesta a esta realidad, se pretendía averiguar cuáles eran los aspectos problemáticos en relación con las medidas de asistencia y protección que se ofrecían a las víctimas de stalking tanto desde el ámbito asistencial como desde el sistema de justicia penal. A juicio de los profesionales entrevistados, se cuenta con numerosos mecanismos legales para proteger a las víctimas de stalking, exponiendo que este tipo de víctimas tienen a su disposición todos los instrumentos de protección existentes con carácter general en el ordenamiento jurídico-penal y destacando, además, que las mismas reciben una protección reforzada cuando el acoso se produce en el marco de la violencia doméstica y/o de género. Así, a menudo $(n=11 ; 40,7 \%)$ se hizo referencia a que medidas judiciales como las órdenes de alejamiento y las órdenes de protección -para los casos en que estas últimas puedan ser aplicadas- son las más adecuadas frente a este tipo de situaciones, ya que propician el distanciamiento entre víctima y victimario.

Además de las medidas judiciales de protección mencionadas, los profesionales nos indicaron que se ofrece protección policial a las víctimas de violencia de género en base al nivel 
de riesgo de la concreta víctima -independientemente del delito padecido-, baremado a través de un cuestionario de 25 preguntas (Valoración Policial del Riesgo, VPR) y de su evolución (Valoración Policial de la Evolución del Riesgo, VPER). Junto a ello, 2 de los profesionales $(7,4 \%)$ hicieron referencia a un servicio telefónico gratuito de atención y protección a las víctimas de violencia de género, conocido como ATENPRO, que permite que las mismas sean atendidas por personal especializado en violencia de género de forma inmediata, especialmente en situaciones de emergencia.

Más allá de los instrumentos protectores apuntados, sin embargo, pese a reconocer como suficientes los mecanismos legales para proteger a las víctimas de stalking, el mayor escollo identificado en términos de protección judicial victimal se sitúa en el periplo que las víctimas deben seguir para obtener protección. A continuación se exponen los principales problemas detectados en la dinámica de funcionamiento de los servicios que entran en contacto con la víctima.

a) Relación entre los servicios asistenciales y el sistema de justicia penal: entre la coordinación y la desconfianza

En primer lugar, respecto a la actuación de los servicios, y más concretamente respecto a las relaciones existentes entre el ámbito asistencial y el sistema de justicia penal, todos los entrevistados manifestaron una intensa coordinación entre los distintos servicios (policía local, Mossos d'Esquadra, servicios asistenciales de ámbito local, comarcal y autonómico, Oficinas de Atención a la Víctima del Delito, Centros de Atención Primaria, centros educativos, etc.) principalmente guiada por los protocolos de actuación en el marco de la violencia de género:

E21: "Que quede muy claro que nuestro abordaje es coordinado. No entendemos una manera de abordar la atención a las víctimas que sea únicamente policial, sino que nos coordinamos con otros agentes sociales con los que mantenemos reuniones de forma habitual ya sea por el caso concreto o de forma genérica. Que formamos parte de los protocolos de la demarcación 
territorial que también tienen que ver con este tipo de objetivo y creo en esta forma de intervenir: de forma coordinada y con otros profesionales."

Pese a ello, uno de los datos más reveladores respecto a la actuación de los servicios de atención a las víctimas tiene que ver con que la mayor parte de los encuestados pertenecientes al ámbito asistencial mostraron una absoluta desconfianza en el sistema judicial -no así en las autoridades policiales-, llegando algunos incluso a desaconsejar la denuncia a las víctimas de stalking atendidas:

E12: "En este caso yo recomendé no denunciar porque no se hubiera conseguido nunca una orden ni una medida judicial. Y finalmente ella optó por marcharse durante un mes y lo solucionó sin la justicia porque era un caso que judicialmente no tenía mucho futuro, él la estaba provocando para que lo denunciara, él quería entrar aquí, en esta guerra judicial, procedimental. Y seguramente hubiera ganado."

E14: "Ya se sabe, y es una información bastante conocida y nosotras las asesoramos de todo lo que puede pasar, no las engañaremos, no les diremos que poner una denuncia es garantía de... porque no depende de nosotras. Entonces ante tener una buena información de lo que es un proceso judicial de lo que es, de que tendrá que estar con el ofensor, de lo que tendrá que revivir, de lo que tendrá que pasar... y después de pasar por todo esto de estar con un cuadro de ansiedad o de síndrome de estrés post-traumático, la mujer valora muchas veces que no le vale la pena poner esta denuncia."

E19: “Ojalá, ojalá nos llegaran más casos de personas que no han denunciado y se les pudiera asesorar. Porque vienen aquí con unas esperanzas y aquí se les truncan."

\section{b) Victimización secundaria}

Quizá el aspecto más problemático de los relacionados con el periplo judicial que recorren las víctimas para ser protegidas identificado por los profesionales se identifica con la victimización secundaria a que pueden verse sometidas, a menudo 
influida por la falta de formación de los operadores jurídicos que entran en contacto con ellas. Así se deduce de los siguientes pasajes:

E9: "Hay muchos abogados que hacen el cursillo de especialización en violencia de género y se ponen en el turno de oficio pero, claro, sensibilizados no están. Entonces llega un momento que muchas encuentran abogados que ni las escuchan, ni les explican las consecuencias y también las cuestionan los abogados. Y después tampoco las informan, no las llaman para preparar el juicio, las mujeres están angustiadas. (...) Me he encontrado con esto un montón de veces y me indigna mucho. Porque en la violencia en general a las mujeres se las cuestiona mucho, es un tema que aún la gente, los profesionales del juzgado no están sensibilizados o no están formados. Entonces es como «iqué exagerada! no hay para tanto», «porque ella se lo ha dejado hacer». Esta idea esta mucho en los juzgados y te encuentras que tienes que luchar contra esto. Son una serie de prejuicios que encuentras en el organismo en que se supone que tú confías, que tú pones denuncias y confías en que se hará justicia. Pero es que llegas allí y se encuentran que «ipor qué no lo has denunciado antes?», «¿por qué no lo has parado?», «¿por qué no te ibas?». Sin tener en cuenta toda la problemática que tiene la mujer, la mujer tiene un lazo muy fuerte con el ofensor, es una dependencia."

E12: "Es muy traumático, nosotros le llamamos, bueno esto está escrito, la victimización secundaria, que es la que hace la Administración sobre la víctima (...). La realidad de la víctima quedaba como muy descuidada, y muy descuidada por el Código Penal y por la justicia en general. Y ahora de unos años hacia aquí se va haciendo más caso. (...) O sea además de que tienes a alguien que te está persiguiendo, que lo estás pasando fatal, y que vas a pedir a ayuda te encuentras con una revictimización. Te encuentras con abogados, con fiscales, con jueces que preguntan muy impertinentemente y en favor del ofensor. Que machacan mucho más a la víctima. A veces los propios abogados defensores no defienden suficiente los derechos de ellas. Con lo cual hay mucho que hacer para las víctimas de delitos graves. Ya llegan suficientemente tocadas para que encima el proceso judicial sea muy duro. Hay mucha literatura sobre victimización secundaria. Nosotros llevamos años viendo de todo.” 
E17: "Ha habido personas que han ido al equipo judicial y han vuelto como si hubieran vuelto a ser maltratadas. No todas pero bueno en los casos de violencia psicológica es más subjetivo y se las cuestiona enseguida. Padecen mucho, han vuelto muy mal. La formación a los profesionales es básica."

E23: "Los juzgados están formados por personas y el grado de conocimiento o de implicación de todas las personas no es el mismo. Cuando la persona entra a la institución policial y en oficinas como la nuestra ya nos forman para considerar esta victimización secundaria y en ningún momento juzgarla, mirar de entenderla y también explicarle lo que se encontrará en el complejo mundo judicial. Todas estas explicaciones ayudan a entender que lo que encontrará por parte del juzgado a veces no será del todo comprensible, y es aquí donde entramos en que en el juzgado se pueden encontrar personas que no tengan estas mismas consideraciones y que acaben comportándose de una manera que le hará sufrir una victimización secundaria."

Uno de los entrevistados resumía las dificultades concurrentes para ponderar el derecho de defensa del encausado con la minimización de esta victimización secundaria, apuntando, sin embargo, a que en la actualidad existe una mayor concienciación por parte de los operadores jurídicos. No obstante, se mostraba escéptico en cuanto a la eliminación total de estos perjuicios ocasionados a la víctima, por considerar que estos son intrínsecos al propio funcionamiento del aparato judicial:

E25: "A veces es un camino muy largo que desgasta a la víctima: múltiples denuncias, declaraciones en el juzgado de instrucción, luego ir al penal, recursos... (...) Claro pero es que tampoco se puede pretender denuncio y nadie me ponga en duda. Es la principal fuente de prueba, hay un derecho de defensa. Desde luego existe la victimización secundaria y las víctimas tienen que saber que no va a ser fácil, pero yo creo que no hay otra alternativa. Es como si tienes una enfermedad grave, vas a pasar por el médico, vas a tener una anestesia, te van a doler los puntos.... Todo eso se puede minimizar si se hace bien, pero yo creo que lamentablemente hay un coste personal en venir a juicio y obviamente hasta ahora, hasta hace 
no mucho, no éramos conscientes los jueces, ni los profesionales, ni el legislador de este coste para la víctima. Ahora somos conscientes, pero por muchas medidas que se adopten yo creo que una persona que lo ha pasado muy mal con su pareja solo el hecho de saber que tienes que ir a juicio y volver a revivirlo aunque no lo vayas a ver, aunque haya un biombo, aunque haya una videoconferencia tiene que ser traumático. Pero no hay otra alternativa, obviamente hay que minimizar, no hay que llamarla aquí 5 veces, hay que intentar evitarlo, hay que hacerlo de la mejor manera posible, en un espacio adecuado, usando nosotros también un lenguaje adecuado, una forma de dirigirnos a ella adecuada. Que no tiene que ser equivalente a no ser contundente, incluso la defensa. Pero pese a todo va a tener que pasar por ese trauma"

\section{c) Dificultad de prueba}

Como ya habían apuntado anteriores investigaciones ${ }^{24}$, el segundo escollo señalado por los profesionales para la adopción de medidas de protección es la dificultad de probar las conductas de acoso predatorio, cosa que se traduce en que en numerosas ocasiones se produzca bien el archivo de las actuaciones, bien la absolución del encausado. Como consecuencia, las medidas de protección victimal en estas circunstancias bien directamente no pueden obtenerse, bien cesan en el momento en que se produce la absolución. En relación con esta problemática, algunos de los entrevistados indicaron:

E9: “- ¿En los casos de acoso se dan muchas absoluciones?

-Sí, porque no se acredita, no hay suficiente prueba. Si la mujer dice es que me está esperando cada día en la puerta de casa, pero claro si no me traes un testimonio que lo diga... Tampoco habrá alguien que esté allí cada día mirando si el coche está aparcado allí."

24 Vid. Morris, S. / Anderson, S. / Murray, L.: Stalking and Harassment in Scotland, op. cit., pp. 68 y ss. y LogAn, T. K.: Research on partner stalking: Putting the pieces together, Department of Behavioral Science \& Center on Drug and Alcohol Research, University of Kentucky, Lexington, 2010, pp. 16-17. 
E12: "Se producen muchas absoluciones por falta de pruebas (...). Si solo hay la palabra de uno y otro... (...) si no hay más pruebas físicas, a parte de los mensajes de móvil y tal... Cuando el ofensor es alguien con un nivel cultural medio - alto, lo complica mucho para la víctima. Muchísimo. (...) Era una cosa terrorífica pero era indemostrable de la forma que lo hacía, porque era todo muy sutil. (...) Hay casos que para la justicia es complejo."

E14: "Como la denuncia realmente es un trámite administrativo, muchas veces se archiva, no procede. Y después que cuando es un juicio rápido, como estos son procesos en los que la víctima tiene que demostrar en el sistema actual que esto es así con pruebas, las pruebas del acoso es difícil demostrarlo. Incluso haciendo vaciados de móvil pues no... Los casos en los que hemos visto que se han otorgado órdenes de alejamiento eran casos en que habían anuncios en internet ofreciendo servicios sexuales, donde el ofensor había puesto este anuncio como si fuera la mujer. O donde había carteles en la calle, que alguien lo ha visto y ha hecho una foto y tal y entonces más pruebas... pero en sí situaciones de acoso en la calle o vía móvil que la persona no ha guardado las conversaciones pues es tu palabra contra la mía. Hay juzgados que funcionan mejor pero, en general, la balanza no está equilibrada. (...) La experiencia nos dice que tampoco podemos confiar en los servicios policiales y del sistema penal porque realmente el stalking es algo muy difícil de demostrar, muchas veces es la palabra de la persona que lo vive."

E19: "Los recursos y todo como son los mismos (que en cualquier otro delito se refiere) son los correctos. Pero el desconocimiento de cómo aplicar este nuevo delito y probarlo... Porque que desde julio de 2015 hasta hoy que estamos a 26 de abril (de 2016 se refiere) que en ninguna sentencia hayan hecho constar el stalking... cuando se está detectando que hay."

E27: "El reconocimiento por parte del investigado de la emisión de determinado número de correos o de la realización de determinadas llamadas de teléfono no sería suficiente, en principio, para la apertura de juicio oral porque sabes que en el acto de juicio se puede desdecir de lo que ha dicho en instrucción o incluso puede guardar silencio, entonces con la jurisprudencia 
del Supremo hay que hacer periciales que nos permitan determinar que esos correos electrónicos se han generado a partir de una IP determinada, de un ordenador determinado, que como sabes es el documento identificativo de cualquier ordenador, y de que, evidentemente, casi con toda la seguridad ese ordenador desde el que se remiten los correos electrónicos o el teléfono desde el que se hacen las llamadas o cualquier otro terminal, estaban a disposición casi exclusiva del investigado. Las dificultades, insisto, son en el momento del juicio (...) yo creo que va a ser complejo poder castigar por un delito de acoso, va a ser muy complejo. No tanto la investigación como la prueba en el plenario. Va a ser complicado. (...)Yo creo que lo que he dicho, el 172 ter CP no va a cubrir las expectativas que creó, y que en muchos casos las conductas se van a poder reconducir posiblemente a otras. También por problemas de prueba, es mucho más fácil desde el punto de vista probatorio y de la investigación penal ir a un delito de coacciones que no a un delito de acoso."

Sin embargo, conscientes de las consecuencias derivadas de la dificultad de probar la existencia del patrón acosador, la mayor parte de agentes policiales (4 de 6; 66,6\%) indicaron que su actuación protectora se produce en función de su propia valoración del nivel de riesgo, independientemente del resultado del proceso penal:

E26: "Nosotros hacemos un seguimiento independientemente de lo que pase en el juicio. No nos vincula. Nosotros si vemos que se le tiene que hacer una protección la hacemos incluso después del juicio. Claro, es que igual el juez ve clarísimo que eso se tiene que condenar pero no tiene herramientas. Entonces por el hecho de no tener herramientas no quiere decir que no esté en riesgo y a partir de aquí si no tenemos una orden o no tenemos una sentencia condenatoria no nos puede detener. Porque a veces se archivan cosas por este motivo. Sería injusto si realmente ves que esta persona tiene un riesgo y no se le ha concedido una orden. No tiene nada que ver, nosotros actuamos igual, nuestra función es proteger, eso está clarísimo." 


\section{d) Insatisfacción de las víctimas con el sistema de jus- ticia penal}

Se decidió además, en orden a averiguar la valoración que podía hacerse del tratamiento institucional prestado a las víctimas, preguntar a las que efectivamente habían llegado a denunciar los hechos. De las entrevistas realizadas con las víctimas puede deducirse, además, en el mismo sentido que apuntan anteriores investigaciones ${ }^{25}$, una absoluta insatisfacción con el sistema de justicia penal, atendiendo tanto al mal funcionamiento de la administración de justicia como a la lentitud del sistema. Así, los entrevistados manifestaban:

E3: "Fue eso lo que denunciamos a los Mossos (...) sí que a la chica le podían... Sé que durante un tiempo ella tenía que hacer trabajos comunitarios (...). Yo como era menor no pude decir nada y la denuncia quedó como en la nada. Pero sí que las denunciamos (...). A parte el proceso penal que es muy lento (...). Por el penal no pasó nada. Hubiera pasado si mi madre en su momento hubiera querido continuar que era lo que yo en realidad quería. Porque si llevo 2 años sufriendo, aunque me tarde 3-4 el proceso penal pero quiero que se les castigue porque ellas han hecho algo que está mal. Entonces mi madre pues no quiso. (...) Sobre todo que fuera mucho más rápido (se refiere al procedimiento penal). Porque la policía en realidad tampoco puede hacer nada, sí que a veces se pasaban más por la salida del instituto y te tenían un poco más como controlada pero nada, no hicieron nada. Que tampoco les pueden hacer

25 Vid. KorkodeiLou, J.: «Stalking victims, victims of sexual violence and criminal justice system responses: is there a difference or just 'business as usual'?», op. cit., pp. 260-267; Maclean, L. / Reiss, D. / Whyte, S. / Christopherson, S. / Petch, E. / Penny, C.: «Psychiatrists' Experiences of Being Stalked: A Qualitative Analysis», en Journal of the American Academy of Psychiatry and the Law, vol. 41, n², 2013, p. 197; Morris, S. / Anderson, S. / Murray, L.: Stalking and Harassment in Scotland, op. cit., pp. 52-55; TAYLOR-Dunn, H. / Bowen, E. / Gilchrist, E. A.: «Reporting Harassment and Stalking to the Police: A Qualitative Study of Victims' Experiences», op. cit., pp. 13-20 y VAN DER AA, S. / GroenEN, A.: «Identifying the Needs of Stalking Victims and the Responsiveness of the Criminal Justice System: A Qualitative Study in Belgium and the Netherlands», op. cit., pp. 19 y ss. 
nada, que no es culpa de la policía, sino de las medidas que hay y de las leyes que hay (...)."

E6: "Hubo problemas porque la denuncia en principio iba en contra mía. Fuimos a los Mossos d'Esquadra y la denuncia llegó al Juzgado de Menores conforme yo era quien agredía a mi padre, finalmente la recolocaron hacia donde tocaba pero se ve que la jueza que llevaba el caso estaba en una época de depresión, no lo supimos hasta unos años después y el caso se archivó (...). Del tema de justicia no hubo ninguna respuesta porque la única repuesta fue archivar el caso, según la jueza por falta de pruebas, pero después descubrimos que llevaba 5 años archivando casos. Después te pedían de reabrirlo si querías pero volver a pasar por lo mismo... Nos dijeron que: «si reabrimos el caso seguramente tu padre acabará en prisión». ¿Y yo que necesidad tengo de que con todo el papeleo, volver a revivir otra vez todo y que mi padre acabe a la prisión por algo que hace tiempo que ha hecho? (...) Yo pienso que en aquel momento o te matan o no pasa nada. Incluso una vez lanzó un móvil porque estaba cabreado y le iba a la cabeza a mi hermana y subí yo la rodilla para parar este golpe. Fui con una rodilla que era el doble de grande de lo normal a urgencias, me hicieron el parte e incluso así ni la jueza me quiso coger el caso. Entonces es que hasta que no te maten no hacen nada."

E15: "La respuesta que recibí fue muy lenta, desde que denuncié los hechos hasta que supe su identidad pasaron unos 8 o 9 meses. La manera con la que descubrí su identidad fue que él me llamó muy enfadado diciéndome que porque lo había denunciado, me dijo que lo acababan de citar los Mossos para un juicio contra mí. (...) Yo seguí recibiendo llamadas cada día y SMS una vez a la semana durante unos meses y cada vez que recibía un SMS lo llevaba a la oficina de los Mossos (...). Cuando se celebró el juicio, el fiscal lo había calificado mal, había calificado el caso de "vejación injusta", así que no sucedió nada más que un susto para él."

\subsection{Posibilidad de alternativas al proceso penal tra- dicional: medidas de carácter tuitivo y justicia restaurativa}

Habiéndose constatado la inadecuación del proceso penal para obtener medidas de protección de forma satisfactoria, 
el cuarto y último de los objetivos de la investigación consistía en averiguar cuál era la opinión de los entrevistados acerca de la articulación de alternativas a este proceso penal tradicional, ya fuera mediante la incorporación de mecanismos de justicia restaurativa dentro del ámbito penal o bien a través de la puesta en funcionamiento de ordenes civiles de protección o de amonestaciones administrativas como se hace en otros países de nuestro entorno jurídico. $\mathrm{Al}$ respecto, puede adelantarse que ninguno de los profesionales tenía conocimiento de la existencia de mecanismos jurídicos de protección al margen del proceso penal en Derecho comparado, por lo que resultó difícil que en las entrevistas afloraran sus puntos de vista sobre tal cuestión. En aquellos casos en los que se insistió en este aspecto, la mayoría de los profesionales se mostraron ya dubitativos ( $n=10 ; 37 \%)$, ya abiertamente en contra de la aplicación de estos mecanismos $(n=5 ; 18,5 \%)$, aun cuando sin ofrecer razones que justificaran este punto de vista más allá de cumplir con lo normativamente establecido. Así algunos de los entrevistados nos decían:

E1: "Por ejemplo en este caso que hemos explicado de momento es respuesta penal porque está en el ámbito penal. Nosotros lo que tenemos que hacer es conseguir saber quién es esta persona, y después se tiene que informar de esta persona al juez, a quien se le informa de que ha sido objeto de un stalking puro y duro (...). Entonces el juez inicia el proceso penal contra esta persona, $(. .$.$) donde nuestra respuesta siempre será inicialmente$ penal porque se ha venido a denunciar un hecho de stalking del 172 ter del Código Penal, y nosotros tenemos que ponerlo en conocimiento de la autoridad judicial, así como también desde el momento en que tengamos conocimiento del autor de los hechos. (...) Se tienen que seguir los pasos."

E27: "El procedimiento civil es inviable porque si ahora mismo tenemos una conducta típica y antijurídica eso exige una respuesta penal."

Por contra, una minoría de los entrevistados $(n=5$; $18,5 \%$ ) se mostró a favor de que el proceso penal tradicional pudiera coexistir con algunos mecanismos alternativos a este, 
pensando sobre todo en que, en algunos casos, la condena puede no ser satisfactoria ni para el ofensor ni para la víctima, en el sentido de no cumplir con las expectativas o propósitos marcados como deseables:

E4: "No tienen por qué ser mutuamente excluyentes estas dos opciones, tendrían que ser posibles las dos. Y es más si continuamos por el lado más penal, prisiones y yo que sé... al final estamos perpetrando algo que no tiene salida. Sí, en la prisión estarán y harán un tratamiento, o no. Así de claro."

E17: "Pienso que ahora mismo podríamos estar combinando los tres. Pienso que tenemos que conseguir unos resultados a corto plazo y entonces es como bueno... pues si hay una pena pues la pena y después ya iremos trabajando la sensibilización a nivel de conductas o a nivel de amor a medio plazo. Pero sí que veo las medidas más restrictivas o más fuertes para intervenir en los casos actuales a corto plazo, y el resto de medidas las de largo plazo empezar ahora para que se vean los resultados a largo plazo. No sé qué se puede hacer en estos casos, un trabajo grupal con este tipo de agresores, no sé, lo desconozco. Pero pienso que una combinación de todas las medidas es lo mejor."

E23: "Como respuestas está bien que estén pero no todas están bien en todos los casos."

E24: "Mi opinión es que la solución no está en el ámbito penal hablando de juicio, pena, sentencia, sino en obligar a esta persona a someterse a un curso de concienciación, en otros sitios sí que existen estos servicios tanto a nivel de obligado judicialmente como a nivel voluntario."

E27: "Yo como penalista (...) eliminaría muchas conductas del Código Penal y efectivamente las llevaría a otro tipo de soluciones diferentes a las del proceso. Que pudiera ser una la del acoso, pues posiblemente sí. Pero me gustaría ver antes de arriesgarme a dar un sí rotundo a ver cómo funciona el tipo penal."

Más proclives se mostraron los entrevistados a hablar sobre su opinión acerca de la posibilidad de arbitrar mecanismos de justicia restaurativa en el marco del proceso penal, a pesar de que la mayoría de ellos centraron esta posibilidad en la me- 
diación penal. $\mathrm{Al}$ respecto, la mayor parte de los profesionales declararon que estaban en contra de la aplicación de tales mecanismos $(n=13 ; 48,1 \%)$ :

E8: "Yo considero que cuando se está dando el stalking, así como cuando la violencia machista está activa, yo creo que la mediación no es posible porque la mediación es cuando hay igualdad. Cuando hay stalking o violencia es que uno está ejerciendo un control sobre el otro, por tanto, un abuso de un poder. Yo tengo un poder sobre ti y tú estás en condiciones inferiores. Y entonces yo creo que no es posible esta mediación."

E13: "Yo pienso que este tipo de delitos, en concreto el stalking, la mejor forma es judicial. Porque a ver este delito implica una permanencia en el tiempo, su comisión. Por un día que la llames 50 veces pues igual acusas por un delito leve de coacciones, de vejaciones... pero cuando una situación delictiva se mantiene en el tiempo, hace falta cierta permanencia en el tiempo eso demuestra una voluntad del ofensor, delictiva, prolongada. Y yo creo que cuando se llega a este tipo de delitos es mejor en el juzgado, porque no estamos hablando de situaciones puntuales, un momento de discusión tensa."

E15: "Sustituirlo por una mediación, es que es hacer algo que ya está hecho y estas poniendo en igualdad a dos personas que no lo están. No es conflicto, es violencia. Hay voluntad de imponerse sobre el otro."

E19: "Lo que pasa que con el tema del acoso... primera que la ley te prohíbe hacer una mediación en temas de violencia de género, pero sí que es verdad que en los casos de acoso yo aún menos creo. Porque una persona que haga el acoso como tal... de llamadas, de irla a encontrar, al sitio de trabajo, de a través de familiares intentarla perjudicar a nivel emocional, una mediación es casi imposible. Que vaya por al ámbito penal que para eso se ha tipificado."

Sin embargo, una minoría de los entrevistados, pese a conocer la prohibición legal de mediación en casos de violencia de género, se mostraron a favor de la aplicación de instrumentos de justicia restaurativa incluso en estos casos $(n=7 ; 25,9 \%)$ : 
E4: "Yo creo que la mediación es posible, lo que pasa que no todo el mundo está disponible para esto. Habrá casos que sí, habrá casos que no."

E7: "Hay casos y casos. Por norma general siempre no, pero puede haber casos. Si la víctima y el encausado están de acuerdo en que se pueda hacer una mediación. Pero sería cada caso en particular. (...) Porque a veces son casos... tiene que haber un reconocimiento por parte del encausado y que la víctima acceda de forma voluntaria."

E9: "Yo creo que no estaría mal una mediación donde ella le pueda decir al hombre lo que pasa, lo que siente cuando él tiene estas conductas con ella. Pero siempre valorando cuál es el momento en que la mujer lo puede hacer, porque claro si estamos en un momento bajo la mujer será incapaz de plantarle cara o decirle lo que pasa. Claro sería ideal que se pudiera hacer pero no sé si habría resultados, no sé si se podría llevar a cabo. Por esta situación, porque la mujer tendría que estar fuerte para poder y no siempre se da... hay mujeres que lloran y lloran y lloran y no son capaces de decirle nada. Si hay casos en que se valora que podría hacer mediación penal en temas de acoso yo haría mediación penal más que familiar."

Algunos de los profesionales $(n=4 ; 14,8 \%)$ que se mostraron en contra de la aplicación de estos instrumentos cuando se trató de supuestos de stalking integrados en un contexto de violencia de género en el ámbito sentimental, sí se mostraron partidarios de acudir a ellos cuando el fenómeno presentaba unas características distintas en que no hubiera una desigualdad patente entre víctima y victimario -por ejemplo, en el caso de violencia doméstica, conocidos, etc.--. Así, algunos de los entrevistados nos exponían:

E6: “Actualmente para los temas de violencia de género no está permitida la mediación pero para mí tiene un fundamento de realidad. En casos de violencia de género y en casos claros de stalking yo entiendo que una mediación no es útil. Otra cosa es cuando existen situaciones donde no hay una descompensación de poder (...). (Cuando) la mujer tiene los recursos es capaz de plantar cara y (cuando) además tiene recursos externos di- 
ces, bueno, sobre este caso una mediación estas tocando las dos líneas de poder y no habría esta deficiencia por temor a tapar determinadas cosas. Pero en casos más clásicos de maltrato de larga duración en que se crea toda esta situación de indefensión aprendida.... La mediación en casos de violencia de género yo entiendo que no es aceptable precisamente por todo lo que puede quedar tapado (...) Este círculo se tiene que cortar, la mediación no sería más que la continuación de este círculo."

E10: "Si aún no has llegado al punto de tengo miedo, me quiero aislar igual sí que sería bueno pero claro se tendría que coger muy al principio. Cuando las relaciones son desiguales es difícil, porque no sabes si la persona víctima hasta qué punto la otra persona la puede machacar o le puede hacer miedo."

E12: "Yo soy muy partidaria de la justicia restaurativa. Por ejemplo si es violencia doméstica si se puede se tiene que mediar porque hay vínculos materno-filial que se tienen que salvar."

E19: “Aquí sí que podría haber una mediación igual, es que jurídicamente las cosas están muy parceladas y te marca mucho. Quizás en violencia filio-parentales $u$ otras violencias dentro del ámbito familiar no se detecta tanto este acoso porque hay una convivencia y porque no se detectan estas situaciones."

Cuando las víctimas fueron preguntadas acerca de la posibilidad de aplicar este tipo de procesos, se constató la existencia de una gran disparidad de opiniones, pues 8 de los 17 entrevistados $(47,1 \%)$ estuvieron en contra de la aplicación de cualquier tipo de mecanismos de justicia restaurativa -si bien el mayoritariamente referido en las entrevistas fue la mediación penal-, mientras que los restantes estuvieron a favor $(52,9 \%)$. Los más contrarios a estos mecanismos exponían:

E3: "No creo demasiado en la mediación porque, ya te digo sí que en el colegio intentaron... primero hablaban conmigo, luego con ellas, venían sus padres, luego venían mis padres, mis hermanos. Sí que intentaron hablar pero es que no se llegaba a nada. Yo estaba sola y ellas eran un grupo muy grande de gente. Y es obvio, que cuando tienes, no sé, 14 años pues que no veían 
más (...). Yo soy más por la vía penal, ya una vez hay tanto conflicto ya no creo tanto en la mediación penal en realidad, y mucho menos cuando se trata de menores (...). Prevención. Una vez que está el problema ya te digo, ya incluso ya ni creo en la mediación (...). Ya te digo, no creo que si yo me pongo en una mesa delante de todas ellas y con un mediador no creo que lleguen a entender todo lo que están causando de daño a otra gente que no tiene la culpa."

E7: “No, la mediación penal en este caso no la hubiera... aparte de que ella voluntariamente no se hubiera prestado... esto ya era una situación penal, penal de insultos, amenazas, ya se había cometido el delito, en el momento en que a mí me insultan públicamente a través de un medio como puede ser el mail y considero que tenemos, por decir algo, 20 testimonios que han recibido insultos contra mí... ya la mediación era una media tinta que por la gravedad del hecho ya no pintaba (...). La posibilidad penal hubiera sido directa, o actúo o no. Una media tinta solo hubiera servido para que nos volviéramos a ver... de recuperarme de alguna manera."

E14: "Un cara a cara es traumático y la existencia de un mediador implica reconocer que existe una situación sin controlar."

En cambio, las víctimas que sí se mostraban favorables al empleo de mecanismos de justicia indicaron:

E5: "Pues mira, esa sí que la hubiera seguido (se refiere a la opción de la justicia restaurativa). No te digo que no. Porque ellos a lo mejor hubieran entendido como me sentía yo.... Yo como eran ellos... a lo mejor hubieran sacado todo lo que te he dicho, el perfil este que te he dicho, a lo mejor es lo que necesitaban hablar con alguien ¿sabes?”

E4: "Quizás sí. Más que nada por un aspecto en concreto. O sea, me gustaría saber quién (...) le dio mi número de teléfono. O sea, lo único. Y saber simplemente si era una broma o si realmente al tío le faltan un par de tornillos. Hombre, sería preferible de todas las opciones. Sí. Ahí sí, no diré que no. Tengo oído que estas cosas son bastante buenas... o sea, son bastante efectivas tanto para un lado como para el otro." 
E6: "Sí, hubiera estado de acuerdo en ese momento de hacer una mediación. Como no hubo ninguna respuesta (por parte del sistema de justicia penal, se refiere) en ese momento, pienso que las cosas se pueden solucionar hablando. De hecho, (...) le pedimos que hubiera una persona mediadora por medio para hablar las cosas, para que así pudiera hablar yo sentirme bien por saber que estoy protegida por la ley, por una persona que está escuchando las cosas, que no se puedan malinterpretar y que él también pudiera decir la suya. Su respuesta fue que no quería, que él no quería ningún intermediario, que era así o así, no le interesaba (...). Si hubiera habido una persona que fuera realmente imparcial, un psicólogo o un mediador específico que no tuviera relación con ninguno de los dos y que no estuviera de ningún lado, supongo que sí que hubiera podido funcionar y se hubieran podido hablar las cosas."

\section{Discusión y conclusiones}

El primer objetivo de la investigación estaba orientado a comprender qué esperan las víctimas de stalking del sistema de justicia penal y cuáles son los motivos que les llevan a no denunciar los hechos. En este sentido, las necesidades más comúnmente afloradas en las entrevistas realizadas con las víctimas fueron tanto la voluntad de dejar de ser objetivo de atención indeseada por parte del ofensor como la protección frente al mismo, opción esta que eligieron frente al castigo en caso de denuncia. Pese a que el deseo de protección constituyó una constante en las entrevistas realizadas, tomando en consideración la baja tasa de denuncia detectada ${ }^{26}$, se decidió preguntar a las víctimas cuáles habían sido los motivos para no denunciar los hechos. Entre las razones aducidas por estas para no denunciar destacan la ausencia de pruebas, el miedo a represalias, la falta de voluntad de castigar al ofensor, considerar que era un tema pri-

26 Vid. Villacampa Estiarte, C. / Pujols Pérez, A.: «Stalking: efectos en las víctimas, estrategias de afrontamiento y propuestas legislativas derivadas», op. cit., pp. 22-24. 
vado, la falta de gravedad suficiente, el déficit de confianza en la efectividad del sistema de justicia penal, así como el temor a la victimización secundaria, en consonancia con lo ya apuntado por otros estudios ${ }^{27}$.

El segundo de los objetivos señalados consistía en analizar el tratamiento institucional ofrecido a las víctimas del fenómeno y para ello, en primer lugar, se indagó acerca del conocimiento que los profesionales tenían sobre el acoso predatorio. En este sentido, de lo apuntado por los resultados de la investigación puede extraerse que no existe entre los profesionales un concepto unitario de stalking y que, si bien estos conocen a grandes rasgos las características propias del fenómeno, ninguno de ellos alcanza a incorporar en su definición los tres elementos esenciales del acoso predatorio convenidos por la doctrina -esto es, la presentación del fenómeno como (1) un curso de conducta reiterado, insidioso y persistente, (2) no querido por la víctima y (3) capaz de causar en esta miedo o inquietud ${ }^{28}$-. Esto puede deberse tanto a una falta de información o formación específica sobre el fenómeno, como a la dificultad para acotar los límites de este patrón de conducta. No obstante, la conclusión más importante que puede extraerse de las definiciones de acoso ofrecidas por los profesionales es que estos tienden a identificar exclusivamente el fenómeno como una manifestación de la violencia doméstica y/o de género. $\mathrm{Al}$ respecto, pese a considerar positiva la consciencia de los profesionales acerca de la vinculación de ambas realidades, que la conceptuación se realice únicamente en base a ellas puede provocar la invisibilización o la falta de detección del acoso predatorio producido en contextos distintos a los que tienen lugar en el marco de procesos de violencia de

27 Vid. Acquadro, M. / Varetto, A.: «Motives to Report Stalking to the Police: A Comparison Between a Large City and a Small Town in Italy», en Journal of Aggresion, Maltreatment and Trauma, vol. 26, 2017, pp. 515 y ss.

28 Vid. Villacampa Estiarte, C: Stalking y derecho denal. Relevancia jurídico-penal de una nueva forma de acoso, op. cit., pp. 41-42. 
género o familiar. Por consiguiente, en punto a la consecución de una mejor detección y atención a las víctimas de este tipo de procesos, debería valorarse la necesidad de proporcionar información sobre el fenómeno a los profesionales que les permitiera esclarecer sus contornos identificadores.

Prosiguiendo con el conocimiento de los profesionales acerca de este fenómeno, y más concretamente con los mecanismos legales orientados tanto a la persecución de estos comportamientos como a la protección de las víctimas, podemos decir que la mayor parte de la muestra era conocedora de tales instrumentos jurídicos. Los profesionales mostraron un amplio conocimiento acerca del tipo penal en vigor desde 2015 -especialmente los integrantes del sistema de justicia penal-, así como de los protocolos de actuación existentes en materia de violencia de género. No obstante, cabe preguntarse si, como ya se ha apuntado respecto a la definición del stalking, el hecho de que únicamente afloren en las entrevistas los protocolos relativos a violencia de género es indicador de que los profesionales solo están tomando conciencia de una parte de la realidad del fenómeno.

Por último, de las declaraciones efectuadas por los profesionales en torno a su nivel de formación o información sobre el fenómeno puede inferirse nuevamente que si bien estos se hallan ampliamente preparados para hacer frente a los supuestos de stalking que constituyen manifestación de violencia doméstica o de género, pueden presentar carencias cuando el fenómeno se exterioriza en otros contextos relacionales o cuando en ellos no puede vislumbrarse una perspectiva de género. Sin embargo, tampoco parece que una formación basada exclusivamente en el análisis jurídico del tipo delictivo, como la que parecen haber recibido algunos de los profesionales integrantes del sistema de justicia penal, ayude a ofrecer una mejor atención a las víctimas. Con dicho fin debería ofrecérseles una formación transversal que contemplara todas las posibles manifestaciones de esta realidad, más cuando de la encuesta de victimización realizada puede desprenderse que no puede concebirse el stalking únicamente desde estas perspectivas - pues ni la prevalencia de victimización por 
sexos observada ( $44 \%$ en las mujeres frente a $33 \%$ en los hombres) ni la relación previa entre víctima y ofensor (solamente el $25 \%$ de los casos de stalking detectados provenían de personas con quien la víctima mantenía o había mantenido una relación sentimental y un $3,9 \%$ provenían de un familiar) permite realizar tal afirmación ${ }^{29}-$. Junto a ello, de lo descrito en los resultados del estudio puede extraerse que mientras los profesionales dedicados a servicios asistenciales denuncian una insuficiencia de recursos formativos y presentan una elevada implicación en la lucha frente a este tipo de comportamientos, los profesionales pertenecientes al sistema de justicia penal -pese a reconocer que no han recibido formación específica respecto a este patrón acosador- se muestran mucho más satisfechos con su grado de conocimiento sobre el fenómeno, pues manifiestan que este no es un aspecto primordial en su práctica diaria, llegando incluso en algunos casos a mostrar cierta falta de sensibilidad hacia esta realidad.

Para la consecución del segundo objetivo de la investigación, se quiso además indagar acerca de la capacidad del sistema para detectar a este tipo de víctimas. Al respecto, de lo apuntado por los profesionales puede extraerse que los comportamientos acosadores que se producen fuera de los contextos de violencia familiar y de género pasan desapercibidos o son incluidos, en realidad, en otras categorizaciones. Tal situación podría ser debida, como ya hemos visto en relación con la conceptuación del fenómeno, a que las conductas de las que se compone el patrón de acoso presentan unas características que hacen difícil su identificación como fenómeno completo en sí mismo y son comúnmente asociadas a simples medios para ejercer el control sobre la víctima que se halla ya inmersa en otros tipos de violencia.

Junto a ello, según se deduce de la investigación efectuada, existen tres elementos que pueden estar contribuyendo a

29 Vid. Villacampa Estiarte, C. / Pujols Pérez, A.: «Prevalencia y dinámica de la victimización por stalking en población universitaria», op. cit., pp. 10 y $15-16$. 
la invisibilización de los supuestos de acoso predatorio que se producen fuera de estos ámbitos. El primero de ellos es la escasa auto-consciencia de las víctimas sobre su propia condición ${ }^{30}$. Así, la reducida tasa de auto-identificación de las víctimas puede haber llevado a que las personas atendidas por los servicios asistenciales o por las autoridades policiales y judiciales sean únicamente aquellas que se han visto inmersas en procesos de victimización sobre los que existe una mayor sensibilización social, como la violencia de género en el seno de la pareja. El segundo motivo que puede estar contribuyendo a esta falta de detección de estos supuestos de stalking es la falta de formación específica de los profesionales, que unida al amplio conocimiento que los mismos tienen sobre violencia de género puede estar contribuyendo a que el stalking sea entendido exclusivamente como una manifestación de esta realidad. Esto pese a que este fenómeno puede darse, en buena lógica, en una variedad mucho más amplia de contextos relacionales y a que no debe necesariamente radicar en las relaciones de género predominantes en la sociedad patriarcal. El último motivo que se desprende de la investigación efectuada respecto de la ausencia de detección de las víctimas de acoso predatorio que lo son fuera del ámbito de la violencia doméstica y de género es la existencia de estereotipos entre los profesionales acerca de quiénes pueden ser víctimas y ofensores del delito de stalking. Tal visión de la realidad puede estar condicionando la detección de otras formas de acoso predatorio que no se adecúen a los prototipos de víctima y victimario asumidos por los profesionales.

En definitiva, pues, existen condicionantes negativos, todos ellos ampliamente influidos por una hegemónica concepción del stalking como violencia de género circunscrita al ámbito de la pareja, que impiden la identificación de las víctimas de acoso predatorio en otros contextos en tres momentos distintos. En primer término, la falta de identificación de la propia víctima como persona acosada puede impedir que estos hechos lleguen a cono-

30 Vid. Villacampa Estiarte, C. / Pujols Pérez, A.: o. u. c., pp. 9-10. 
cimiento de los profesionales, a no ser que las conductas vengan acompañadas de procesos de victimización de mayor calado o sobre los que existe una mayor concienciación. En un segundo momento, la falta de formación específica de los profesionales sobre el stalking, unida a la existencia de perfiles de víctimas y victimarios preconcebidos y estereotipados, ha podido contribuir a que algunas víctimas de stalking que no se adecuen a estos estándares prefijados no hayan sido detectadas por el sistema. Finalmente, las víctimas que han llegado al circuito -principalmente a consecuencia del padecimiento de otras conductas sobre las que existe una mayor sensibilización- no han sido tratadas específicamente como víctimas de stalking, sino habitualmente como víctimas de violencia de género en el ámbito de la pareja, sin detectar el stalking como un fenómeno autónomo y diferenciado de otros tipos de victimización.

Constituía el tercer objetivo de la investigación valorar los mecanismos legales existentes para hacer frente a estas situaciones de acoso, tanto los integrados en el derecho penal sustantivo, cuanto los previstos en el proceso penal. En primer lugar, esta valoración se realizó respecto a la respuesta jurídicopenal otorgada por el ordenamiento español a estas conductas. En lo que a esto se refiere, de lo apuntado por los profesionales puede deducirse que se entiende como positiva y necesaria la introducción de un tipo penal específico para hacer frente a las conductas de stalking, tanto por la visibilización que el derecho penal puede dar a este fenómeno como por el vacío legal existente hasta la específica incriminación de estas conductas, que se traducía en la imposibilidad de dar una adecuada respuesta penal a las mismas, al menos cuando no acontecían al mismo tiempo que otros comportamientos que ya gozaban de relevancia penal. Sin embargo, la introducción de este nuevo tipo penal específico tal como se halla redactado ha originado cierto malestar entre los operadores jurídicos, tanto por la falta de claridad en la redacción del artículo como, específicamente, por la ausencia de determinación del resultado típico que, quedando concretado en «la grave alteración del desarrollo de la vida cotidiana de la 
víctima», admite interpretaciones subjetivas y crea un área de incertidumbre que preocupa a los profesionales.

Por lo que se refiere, en segundo lugar, a las medidas judiciales de protección a las víctimas, pese a considerarse que estas son suficientes para luchar contra este tipo de comportamientos, se advierte por parte de los profesionales que el procedimiento para obtenerlas resulta excesivamente arduo. Los principales problemas identificados al respecto fueron tanto la victimización secundaria a la que la víctima se ve sometida a su paso por el proceso judicial, como la inefectividad del propio proceso en lo que a la consecución de medidas protectoras se refiere, atendiendo al habitual archivo del caso y a la absolución del ofensor por falta de pruebas. Tales dificultades tienen como consecuencia la falta de confianza en el sistema judicial por parte de los profesionales del ámbito asistencial y de la propia ciudadanía, cosa que se traduce en una reducida tasa de denuncia de esta forma de criminalidad. Así, de lo apuntado por los profesionales puede extraerse que la ausencia de denuncia puede, en ocasiones, verse inducida por el propio sistema asistencial. Existe, en este sentido, una desconfianza generalizada hacia el sistema judicial entre los integrantes de los servicios de asistencia a las víctimas -que incluso se extiende a aquellos servicios que mantienen un mayor contacto con la administración judicial, como las Oficinas de Atención a la Víctima del Delito-. Con todo, los argumentos esgrimidos por estos profesionales para desaconsejar la denuncia se refieren básicamente a dos aspectos problemáticos, reconocidos también por los integrantes del sistema de justicia penal, ya apuntados supra: la victimización secundaria y la dificultad de probar los hechos delictivos. De hecho, las entrevistas realizadas a las víctimas desvelan una absoluta insatisfacción con el sistema de justicia penal por parte de aquellas personas que sí han denunciado los hechos, atendiendo tanto al mal funcionamiento de la administración de justicia como a la lentitud del sistema. Además de lo ya apuntado por los profesionales respecto a la dificultad de prueba y al habitual archivo del caso, las víctimas añaden al respecto otros motivos como la incorrecta calificación 
de los hechos y la pasividad y los equívocos de los operadores jurídicos, que tienen como consecuencia la ineficacia del sistema para poner fin a la situación de acoso.

En definitiva, podemos apuntar que pese a que el ordenamiento jurídico-penal cuenta con mecanismos protectores suficientes para hacer frente a los supuestos de stalking, la forma de articular la aplicación de estos instrumentos de protección no resulta adecuada. Los problemas que logran identificarse -básicamente la victimización secundaria provocada por el sistema y la dificultad para probar los hechos-, según se expone intrínsecos al propio funcionamiento de la administración de justicia, derivan en una desconfianza tanto a nivel de los profesionales encargados de la atención victimal como a nivel social en general $^{31}$, que provoca que muchas de las víctimas de stalking no lleguen a denunciar los hechos. La consecuencia que de esto se deriva es la necesaria renuncia a todo el acervo de medidas judiciales disponibles en nuestro ordenamiento jurídico-penal, puesto que estas únicamente pueden obtenerse a través del paso por un proceso judicial. De ahí que quepa plantearse la necesidad de articular otros mecanismos únicamente tuitivos en los que se evite tal nivel de victimización por parte de las instituciones y que permitan la obtención de medidas de protección al margen del derecho penal. En consecuencia, consideramos que, adoptando un punto de vista victimocéntrico, deberían articularse mecanismos de carácter únicamente tuitivo que permitiesen la aplicación de medidas protectoras de una forma más rápida y sencilla que el paso por un proceso penal, como se hace en otros países de nuestro entorno jurídico-cultural.

El cuarto y último objetivo de la investigación consistía en explorar la receptividad a la incorporación de nuevos procesos bien de justicia restaurativa bien de carácter tuitivo alternativos al proceso penal en la respuesta ofrecida por el ordenamiento jurídico frente a estos comportamientos. Al respecto, a pesar

31 Vid. FRA - European Union Agency for Fundamental Rights: Violence against women: an EU-wide survey. Main results, op. cit., pp. 91-92. 
de que los profesionales reconocen la existencia de desajustes en el actual sistema judicial, se muestran algo reacios a introducir modificaciones, especialmente por lo que se refiere a la articulación de mecanismos dispuestos ad hoc para la consecución de medidas protectoras al margen del derecho penal. No obstante, puede apuntarse que quizás estas reticencias sean fruto del desconocimiento sobre el funcionamiento y la efectividad de dichos mecanismos tuitivos. En otro orden de cosas, tampoco el recurso a la justicia restaurativa para abordar esta realidad parece tener mucha acogida entre los profesionales, que en su mayoría se muestran poco partidarios de la aplicación de tales mecanismos alternativos al proceso penal, especialmente en aquellos supuestos de stalking vinculados a la violencia de género en el ámbito sentimental. Sin embargo, cabe matizar que, cuando los supuestos de acoso predatorio se dan en otros contextos, el número de profesionales que contemplan la posibilidad de ofrecer mecanismos de justicia restaurativa se incrementa de forma notable. En consecuencia, no puede descartarse que las reticencias nacidas en torno a la aplicación de instrumentos de justicia restaurativa en los casos de violencia de género se hayan visto influidas por la prohibición del recuso a la medición incorporada en virtud de la LO 1/2004, que puede haber calado hondo en el parecer de los profesionales. Entre las víctimas, la opinión acerca del recurso a la justicia restaurativa se halla más dividida, por cuanto prácticamente la mitad de ellas se mostraron contrarias a la mediación penal al considerar que esta resultaría inefectiva para poner fin a la situación, así como que debería tratarse de una medida reservada para casos más leves, además de apelar al temor de afrontar un encuentro con el ofensor.

\section{Bibliografía}

ACQuadro, M. / Varetto, A.: «Motives to Report Stalking to the Police: A Comparison Between a Large City and a Small Town in Italy», en Journal of Aggresion, Maltreatment and Trauma, vol. 26, 2017, pp. 507-524. 
Bodelon, E. / Igareda, N. / Casas, G.: Violencia sexual, acoso y miedo al delito. Informe Español, Barcelona, 2012.

Braun, V. / Clarke, V.: «Using Thematic analysis in Psychology», en Qualitative Research in Psychology, vol. 3, n², 2006, pp. 77-101.

BREWSTER, M. P.: Exploration of the Experiences and Needs of Former Intimate Stalking Victims, Final Report Submitted to the National Institute of Justice, US Department of Justice, West Chester, 1998.

Cox, L. / Speziale, B.: «Survivors of Stalking. Their Voices and Lived Experiences», en Affilia: Journal of Women and Social Work, vol. 24, nº1, 2009, pp. 5-18.

Denzin, N.K. / Lincoln, Y.S.: «Introduction. The Discipline and Practice of Qualitative Research», en DenZIN, N. K. I Lincoln, Y. S. (Eds.): The Sage Handbook of Qualitative Research, $3^{\text {rd }}$ edition, Sage Publications, Londres, 2002, pp. 1-19.

Finch, E.: The Criminalisation of Stalking: Constructing the Problem and Evaluating the Solution, Cavendish Publishing, Londres, 2001.

Farrell, G. / Weisburg, D. / Wyckoff, L.: «Survey results suggest need for stalking training», en The Police Chief, vol. $67, \mathrm{n}^{\circ} 10,2000$, pp. 162-167.

FRA - European Union Agency for Fundamental Rights: Violence against women: an EU-wide survey. Main results, Publications Office of the European Union, Luxemburgo, 2015.

Galeazzi, G. M. / Bučar-Ručman, A. / DeFazio, L. / Groenen, A.: «Experiences of Stalking Victims and Requests for Help in Three European Countries. A survey», en European Journal on Criminal Policy and Research, vol. 77, 2009, pp. 243-260.

Hoffmann, J.: Stalking, Springer, Heidelberg, 2006.

Isituto Nazionale di Statistica: La violenza e i maltrattamenti contro le donne dentro e fuori la famiglia. Anno 2006, Roma, 2007. 
Klein, A. / Salomon, A. / Huntington, N. / Dubois, J. / Lang, D.: A Statewide Study of Stalking and Its Criminal Justice Response, NCJ Publication \# 228354, National Institute of Justice, U.S. Department of Justice, Sudbury, 2009.

Korkodeilou, J.: «Dealing with the unknown: Learning from stalking victims' experiences», en Crime Prevention and Community Safety: An International Journal, vol. 16, nº 4 , 2014, pp. 253-268.

Korkodeilou, J.: "Stalking victims, victims of sexual violence and criminal justice system responses: is there a difference or just 'business as usual'?», en British Journal of Criminology, vol. 56, 2016, pp. 256-273. https://doi.org/10.1093/bjc/azv054

Logan, T. K.: Research on partner stalking: Putting the pieces together, Department of Behavioral Science \& Center on Drug and Alcohol Research, University of Kentucky, Lexington, 2010.

Maclean, L. / Reiss, D. / Whyte, S. / Christopherson, S. / Petch, E. / Penny, C.: «Psychiatrists' Experiences of Being Sta1ked: A Qualitative Analysis», en Journal of the American Academy of Psychiatry and the Law, vol. 41, $\mathrm{n}^{\circ} 2$, 2013, pp. 193-199.

Melton, H. C.: «Stalking in the context of Intimate Partner Abuse. In the Victims' Words», en Feminist Criminology, vol. 2, nº 4, 2007, pp. 347-363.

Morris, S. / Anderson, S. / Murray, L.: Stalking and Harassment in Scotland, Scottish Executive Social Research, Edimburgo, 2002.

NikuPeteri, A.: «Stalked lives: Finnish women's emotional experiences of post-separation stalking», en Nordic Social Work Research, vol. 7, 2017, pp. 6-17.

Office for National Statistics: «Intimate Personal Violence and Partner Abuse», en Focus on Violent Crime and Sexual Offences: Year ending March 2015, 2016.

Purcell, R. / Pathé, M. / Mullen, P. E.: «The Prevalence and Nature of Stalking in the Australian Community», en 
Australian and New Zealand Journal of Psychiatry, vol. 36, 2002, pp. 114-120.

Scottish Government Social Research: Scottish Crime and Justice Survey 2014/15: Sexual Victimisation and Stalking, Edimburgo, 2016.

Sheridan, L. / Davies, G.M. / Boon, J. C. W.: «The Course and Nature of Stalking: A Victim Perspective», en The Howard Journal, vol. 40, n³, 2001, pp. 215-234. https://doi.org/10.1111/1468-2311.00204

Taylor-Dunn, H. / Bowen, E. / Gilchrist, E. A.: «Reporting Harassment and Stalking to the Police: A Qualitative Study of Victims' Experiences», en Journal of Interpersonal Violence, vol. 22, 2018, pp. 1-28.

VAn der Aa, S. / Groenen, A.: «Identifying the Needs of Stalking Victims and the Responsiveness of the Criminal Justice System: A Qualitative Study in Belgium and the Netherlands», en Victims and Offenders, vol. 6, 2010, pp. 19-37.

Villacampa Estiarte, C.: Stalking y derecho penal. Relevancia jurídico-penal de una nueva forma de acoso, Iustel, Madrid, 2009.

Villacampa Estiarte, C. / Pujols Pérez, A.: «Prevalencia y dinámica de la victimización por stalking en población universitaria», en Revista Española de Investigación Criminológica, $\mathrm{n}^{\circ}$ 15, 2017, pp. 1-27.

Villacampa Estiarte, C. / Pujols Pérez, A.: «Stalking: efectos en las víctimas, estrategias de afrontamiento y propuestas legislativas derivadas», en Indret: Revista para el Análisis del Derecho, n², 2017, pp. 1-33.

Worsley, J. D. / Wheatcroft, J. M. / Short, E. / Corcoran, R.: «Victims' Voices: Understanding the Emotional Impact of Cyberstalking and Individuals' Coping Responses», en SAGE Open, 2017, pp. 1-13. 